\title{
APOLLO 17 NEUTRON STRATIGRAPHY - SEDIMENTATION AND MIXING IN THE LUNAR REGOLITH
}

\author{
DAVID B. CURTIS and G. J. WASSERBURG
}

Charles Arms Laboratory, Division of Geological and Planetary Sciences, California Institute of Technology, Pasadena, Calif., U.S.A.

\begin{abstract}
We have measured shifts in the isotopic abundances of $\mathrm{Gd}$ and $\mathrm{Sm}$ in soils from the Apollo 17 deep drill stem and calculated the neutron fluence from these measurements. The measurements show two well defined regions of nearly constant fluence: (1) a thick deep section with a very large neutron fluence, and (2) a thinner shallow region with a small fluence. This depth dependence is most plausibly described by a model of rapid accumulation in the last $100-200$ m.y., the layered structure reflecting accumulations of isotopically homogeneous source material. This interpretation is compatible with a variety of other characteristics of the soils, including the spallation produced ${ }^{126} \mathrm{Xe}$ normalized to target element abundances.

An alternative model of deposition, followed by irradiation without mixing, followed by shallow mixing will quantitatively describe the data. The model yields an age of $1.25 \mathrm{AE}$ for the bottom of the drill stem. This model was rejected because of the implausible requirement that the soils from the drill stem be accumulated from a source of unirradiated material.

The uniformity of various properties of soils provides criteria for defining major stratigraphic intervals in the drill stem which differ from those identified by the Preliminary Examination Team.

Neutron fluences measured on shallow and deep soils from all lunar landing sites have been normalized to irradiation in an arbitrary standard chemical environment. We infer from histograms of the normalized fluences that there is a distinct difference in neutron fluence between shallow and deep samples which implies a general vertical stratification of neutron fluence in the lunar regolith.

The regolith can be divided into three vertical regions: (1) a well mixed surface layer, $\sim 100 \mathrm{~g} \mathrm{~cm}^{-2}$ thick, with an average fluence of $2.3 \times 10^{16} \mathrm{n} \mathrm{cm}^{-2}$, (2) a poorly mixed zone extending from $100 \mathrm{~g} \mathrm{~cm}^{-2}$ to at least $500 \mathrm{~g} \mathrm{~cm}^{-2}$ with an average fluence of $3.5 \times 10^{16} \mathrm{n} \mathrm{cm}^{-2}$, and (3) a deep layer of lightly irradiated materials $\left(<10^{16} \mathrm{n} \mathrm{cm}^{-2}\right)$. Analysis of this stratification, using a vertical mixing model, indicates that the probability of mixing to several hundred $\mathrm{g} \mathrm{cm}^{-2}$ is comparable to the probability of mixing to several $\mathrm{kg} \mathrm{cm}^{-2}$. This is in contrast to the depth-cratering rate models which have been inferred from crater size frequency distributions using a power law. Alternatively, this discrepancy can be resolved if the true ${ }^{157} \mathrm{Gd}$ capture rate is $\frac{1}{3}$ of the value calculated by Lingenfelter et al. (1972). The most plausible interpretation is that vertical mixing models are not an adequate description of relatively rare deep cratering events which result in significant lateral heterogeneity and addition of unirradiated material to the lunar surface.
\end{abstract}

\section{Introduction}

The systematic study of regolith samples is critical to the understanding of the mechanisms and rates of transport and deposition on the lunar surface. One of the methods which has proven useful in this matter is the measurement of nuclides produced by cosmic ray interactions with nuclei in the regolith. A number of studies have been carried out using both radioactive and stable nuclides. In particular, the stable nuclides produced by cosmic ray interactions are a direct measure of the total time that the soil particles have been in the nuclear active zone which comprises the outer few meters of the lunar surface. Previous workers have studied the total neutron fluence in soil samples from the upper few centimeters of the regolith and in samples from greater depth taken with the deep drill stem (Eugster et al., 1970b; Burnett et al., 1971; Russ et al., 1972; Russ, 1973). The study by Russ et al. (1972) on the deep drill 
stem from Apollo 15 showed that the neutron fluence, as measured by isotopic shifts in ${ }^{158} \mathrm{Gd} /{ }^{157} \mathrm{Gd}$ and in ${ }^{150} \mathrm{Sm} /{ }^{149} \mathrm{Sm}$, was remarkably smooth as a function of depth and appeared to reflect a simple history of material which had been undisturbed for the past $\sim 500 \mathrm{~m} . \mathrm{y}$. Based on these results considerable efforts were made to reach greater depths with the drilling operation during the Apollo 17 mission and one additional section was added to the drill string. The Apollo 17 drilling operation was carried out by astronauts Eugene A. Cernan and Harrison H. Schmitt who recovered a drill stem that sampled nearly three meters of lunar regolith. This core represents the deepest continuous sampling made in the lunar surface. In addition to the drill stem, surface soils were collected at the Apollo 17 site, using a rapid sampling technique, which represent a greater variety and more complete areal coverage than had been obtained on previous missions.

In this study we report on Gd isotopic ratios in ten samples representing nearly the entire depth of the drill stem and surface samples which constitute a limited survey of soils from the Taurus Littrow Valley. In addition, Sm isotopic ratios were measured on selected samples as an independent neutron monitor and to further identify differences between the observed energy spectrum of the neutron flux and the theoretical energy spectrum as calculated by Lingenfelter et al. (1972) (hereafter referred to as $\mathrm{LCH}$ ). The abundances of $\mathrm{K}, \mathrm{Rb}, \mathrm{Sr}$ and $\mathrm{Ba}$ were determined as an index of the chemical composition of the different samples and because some of these elements are important targets for $\mathrm{Kr}$ and $\mathrm{Xe}$ production by cosmic ray interactions.

\section{Experimental}

\subsection{SAMPLING}

All drill stem samples, except those from section 70008, were from the top junction of the drill stem section (upper $0.5-1 \mathrm{~cm}$ ). The four samples from 70008 were taken from various parts of the drill stem (Duke and Nagle, 1974). The depths from which the samples were taken, in units of $\mathrm{g} \mathrm{cm}^{-2}$, were calculated using the sample density for each section as reported in the Apollo 17 Lunar Sample Information Catalog (1973), and the depth in $\mathrm{cm}$ below the lunar surface as reported by the Apollo 17 Preliminary Examination team (PET) (1973). The depths in $\mathrm{cm}$ and in $\mathrm{g} \mathrm{cm}^{-2}$ are given in Table III.

Samples 72501 and 72701 are surface soils from station 2 . They are believed to be talus from the South Massif, an observation which is confirmed by chemical abundances which are characteristic of highlands material (PET, 1974). Sample 70181 was taken from the surface near the ALSEP site, three meters from the deep drill stem, and is assumed to be representative of the surface soil at the deep drill site. The chemical composition of this soil suggests that it is largely comminuted local basalt. Sample 74241 is gray soil which was found near the rim of Shorty Crater adjacent to the unusual deposits of orange soil.

\subsection{Chemical AND MASS SPECTROMETRIC PROCEDURES}

All samples were sieved and the $-300 \mu$ portions were split to provide about $50 \mathrm{mg}$ 
of working material. This sample size contained sufficient quantities of rare earth elements $\left(\sim 5 \times 10^{-7} \mathrm{~g}\right)$ to provide stable beam currents of $>10^{-12}$ amp in the mass spectrometer over periods of several hours.

The procedures used to measure the $\mathrm{Gd}$ and $\mathrm{Sm}$ isotopic ratios are identical to those used previously in this laboratory. A detailed description of the chemical separations may be found in Eugster et al. (1970a). Gadolinium isotopic ratios were measured on the Lunatic I mass spectrometer. Mass spectrometric techniques and the methods of data rejection and calculation are discussed in Eugster et al. (1970), Russ et al. (1972), and Russ (1973). The Sm isotopic ratios were measured on the Lunatic III mass spectrometer; pertinent discussions as to the methodology may be found in Russ et al. (1972) and Russ et al. (1971). A detailed discussion of the chemical and mass spectrometric procedures for Gd and Sm may be found in Russ (1974).

Two blank determinations indicated that less than $2 \times 10^{-11} \mathrm{~g}$ of $\mathrm{Gd}$ were introduced by the chemical procedures, a quantity which does not affect the results.

The Sm blank was not explicitly measured. However, measurements on Sm separated from unspiked blanks gave maximum signals which were $0.1 \%$ of the minimum signal used in measuring $\mathrm{Sm}$ isotopic ratios in samples.

Concentrations of $\mathrm{K}, \mathrm{Rb}, \mathrm{Sr}$ and $\mathrm{Ba}$ were measured on the deep drill stem samples using mass spectrometric isotope dilution techniques. Before dissolution, spikes for $\mathrm{K}, \mathrm{Rb}$ and $\mathrm{Sr}$ were added to the samples. After dissolution, a measured aliquot of $\sim 5 \%$ was taken from each sample and spiked with ${ }^{136} \mathrm{Ba}$. Barium spike was not added to the original sample solution to avoid the possibility of interferences of $\mathrm{Ba}$ isotopes with the measurement of the REE isotopic ratios. Small portions of the aliquots were evaporated on oxidized Ta filaments, which had been outgassed at 5 amp for two hours. Potassium, $\mathrm{Rb}, \mathrm{Ba}$ and $\mathrm{Sr}$ were measured on the same filament load on the Lunatic III spectrometer, each element having a unique range of temperatures at which it is evaporated from the filament. We feel the uncertainties in the alkali and alkaline earth abundances are no more than 3-4\%.

\section{Results}

\subsection{ISOTOPIC RATIOS}

To compare the results of this study with previous work from this laboratory we measured the terrestrial $\mathrm{Gd}$ and $\mathrm{Sm}$ isotopic ratios in solutions of normal salts, and in Knippa basalt which had been enriched in isotopically normal Gd and $\mathrm{Sm}$. The mean value of the measurements is presented in Tables I and II. A summary of the terrestrial ratios previously measured in this laboratory is included in Tables I and II. The agreement is within the uncertainty of the measurements. To further verify the compatability of our results and previous ones we determined Gd isotopic ratios on a split of sample 60501 previously measured by Russ (1973). The results are shown in Table I and are in agreement within the precision of the measurements except for the $\left({ }^{157} \mathrm{Gd} /{ }^{160} \mathrm{Gd}\right)$ ratio. The magnitude of the difference is insignificant to the conclusions of this work. 
TABLE I

Gadolinium isotopic composition ${ }^{\mathrm{a}}$

\begin{tabular}{|c|c|c|c|c|c|c|c|}
\hline & No. of sets & & & & No. of sets & & \\
\hline Sample & $155-158 \mathrm{Gd}$ & ${ }^{158} \mathrm{Gd}$ & ${ }^{157} \mathrm{Gd}$ & $\overline{155 \mathrm{Gd}}$ & $\overline{152,154} \mathrm{Gd}$ & ${ }^{15} \overline{4} \mathrm{Gd}$ & ${ }^{152} \mathrm{Gd}$ \\
\hline & ${ }^{160} \overline{G d}$ & $\overline{{ }^{160} \mathrm{Gd}}$ & $\overline{{ }^{160} \mathrm{Gd}}$ & ${ }^{160} \mathrm{Gd}$ & ${ }^{160} \mathrm{Gd}$ & $\overline{{ }^{160} \mathrm{Gd}}$ & $\overline{1^{160} \mathrm{Gd}}$ \\
\hline Terrestrial $^{c}$ & 263 & 1.13583 & 0.71591 & 0.67689 & 84 & 0.09973 & 0.00928 \\
\hline & & \pm & \pm & \pm & & & \pm \\
\hline Terrestrial & 45 & 1.13584 & 0.71595 & 0.67692 & 14 & 0.09972 & - \\
\hline $60501.31^{d}$ & 24 & 1.14000 & 0.71024 & 0.67479 & 15 & 0.09967 & 0.00938 \\
\hline & & 8 & 6 & 8 & & 4 & 1 \\
\hline 60501.31 & 29 & 1.14003 & 0.71041 & 0.67494 & 10 & 0.09950 & 0.00938 \\
\hline & & 9 & 6 & & & 5 & 1 \\
\hline 14148.193 & 29 & 1.13757 & 0.71362 & 0.67594 & 10 & 0.09976 & 0.00932 \\
\hline & & 9 & 7 & 11 & & 10 & 3 \\
\hline 72701.38 & 5 & 1.13762 & 0.71348 & 0.67609 & & - & - \\
\hline & & 16 & 16 & 25 & & & \\
\hline 72501 & 29 & 1.13751 & 0.71364 & 0.67603 & 9 & 0.09954 & 0.00932 \\
\hline & & 6 & 6 & 7 & & 17 & 4 \\
\hline 74221 & 22 & 1.13606 & 0.71551 & 0.67709 & 8 & 0.09986 & 0.00939 \\
\hline & & 9 & 8 & 7 & & 9 & 2 \\
\hline 70181 & 29 & 1.13697 & 0.71443 & 0.67636 & 10 & 0.09968 & 0.00933 \\
\hline & & 9 & 9 & & & 12 & 1 \\
\hline 70008.189 & 27 & 1.13654 & 0.71473 & 0.67632 & 10 & 0.09980 & 0.00942 \\
\hline & & 11 & 11 & 14 & & 3 & 6 \\
\hline 70008.221 & 29 & 1.13672 & 0.71470 & 0.67641 & 10 & 0.09960 & 0.00936 \\
\hline & & 9 & 7 & 8 & & 5 & 2 \\
\hline 70008.232 & 23 & 1.13665 & 0.71457 & 0.67636 & 11 & 0.09987 & 0.00940 \\
\hline & & 10 & 8 & 9 & & 7 & 1 \\
\hline 70008.183 & 18 & 1.13761 & 0.71346 & 0.67586 & 5 & 0.09974 & 0.00938 \\
\hline & & 15 & 9 & 13 & & 23 & 29 \\
\hline 70006.9 & 20 & 1.13818 & 0.71270 & 0.67555 & 10 & 0.09994 & 0.00946 \\
\hline & & 13 & 11 & 12 & & 8 & 2 \\
\hline 70005.9 & 22 & 1.13829 & 0.71264 & 0.67562 & 10 & 0.09986 & 0.00942 \\
\hline & & 12 & & & & 5 & 2 \\
\hline 70004.9 & 20 & 1.13835 & 0.71270 & 0.67565 & 3 & 0.09973 & 0.00942 \\
\hline & & & 9 & & & 1 & 5 \\
\hline 70003.9 & 21 & 1.13879 & 0.71219 & 0.67557 & 10 & 0.09970 & 0.00940 \\
\hline & & 12 & 10 & 12 & & 6 & 3 \\
\hline 70002.9 & 29 & 1.13853 & 0.71245 & 0.67556 & 10 & 0.09989 & 0.00944 \\
\hline & & 11 & 8 & 12 & & 7 & 1 \\
\hline 70001.9 & 21 & 1.13844 & 0.71227 & 0.67549 & 10 & 0.09998 & 0.00965 \\
\hline & & 11 & 11 & 10 & & 8 & 3 \\
\hline
\end{tabular}

a Normalized to ${ }^{156} \mathrm{Gd} /{ }^{160} \mathrm{Gd}=0.9361$. Errors are $2 \sigma_{\text {mean }}$.

b A set consists of 10 ratios for a given pair of isotopes.

e Eugster et al. (1970b), Russ (1974).

d Russ (1973). 
TABLE II

Samarium isotopic composition ${ }^{\text {a }}$

\begin{tabular}{|c|c|c|c|c|c|c|}
\hline Sample & $\begin{array}{l}\text { Number of } \\
\text { ratios }\end{array}$ & $\frac{{ }^{152} \mathrm{Sm}}{{ }^{154} \mathrm{Sm}}$ & $\frac{{ }^{150} \mathrm{Sm}}{{ }^{154} \mathrm{Sm}}$ & $\frac{{ }^{149} \mathrm{Sm}}{{ }^{154} \mathrm{Sm}}$ & $\frac{{ }^{148} \mathrm{Sm}}{{ }^{154} \mathrm{Sm}}$ & $\frac{{ }^{144} \mathrm{Sm}}{{ }^{154} \mathrm{Sm}}$ \\
\hline Terrestrial $^{\mathrm{b}}$ & 1605 & $\begin{array}{r}1.17537 \\
\pm \quad 4\end{array}$ & $\begin{array}{r}0.32440 \\
\pm \quad 2\end{array}$ & $\begin{array}{r}0.60750 \\
\pm \quad 2\end{array}$ & $\begin{array}{c}0.49419 \\
\pm \quad 2\end{array}$ & $\begin{array}{l}0.13516 \\
\pm \quad 1\end{array}$ \\
\hline Terrestrial & 460 & $\begin{array}{r}1.17520 \\
6\end{array}$ & $\begin{array}{r}0.32437 \\
3\end{array}$ & $\begin{array}{r}0.60755 \\
4\end{array}$ & $\begin{array}{r}0.49426 \\
4\end{array}$ & $\begin{array}{r}0.13518 \\
3\end{array}$ \\
\hline 60501 & 140 & $\begin{array}{r}1.17530 \\
15\end{array}$ & $\begin{array}{r}0.32696 \\
9\end{array}$ & $\begin{array}{r}0.60497 \\
11\end{array}$ & $\begin{array}{r}0.49417 \\
12\end{array}$ & $\begin{array}{r}0.13526 \\
9\end{array}$ \\
\hline 14148 & 193 & $\begin{array}{r}1.17511 \\
9\end{array}$ & $\begin{array}{r}0.32538 \\
5\end{array}$ & $\begin{array}{r}0.60594 \\
7\end{array}$ & $\begin{array}{r}0.49418 \\
6\end{array}$ & $\begin{array}{r}0.13520 \\
4\end{array}$ \\
\hline 74241 & 162 & $\begin{array}{r}1.17544 \\
13\end{array}$ & $\begin{array}{r}0.32468 \\
6\end{array}$ & $\begin{array}{r}0.60724 \\
9\end{array}$ & $\begin{array}{r}0.49417 \\
8\end{array}$ & $\begin{array}{r}0.13518 \\
6\end{array}$ \\
\hline 70181 & 195 & $\begin{array}{r}1.17542 \\
11\end{array}$ & $\begin{array}{r}0.32533 \\
7\end{array}$ & $\begin{array}{r}0.60664 \\
8\end{array}$ & $\begin{array}{r}0.49418 \\
8\end{array}$ & $\begin{array}{r}0.13519 \\
6\end{array}$ \\
\hline 70008.232 & 225 & $\begin{array}{r}1.17540 \\
10\end{array}$ & $\begin{array}{r}0.32526 \\
6\end{array}$ & $\begin{array}{r}0.60669 \\
7\end{array}$ & $\begin{array}{r}0.49423 \\
6\end{array}$ & $\begin{array}{r}0.13512 \\
5\end{array}$ \\
\hline 70008.183 & 237 & $\begin{array}{r}1.17515 \\
8\end{array}$ & $\begin{array}{r}0.32585 \\
4\end{array}$ & $\begin{array}{r}0.60599 \\
6\end{array}$ & $\begin{array}{r}0.49421 \\
5\end{array}$ & $\begin{array}{r}0.13521 \\
4\end{array}$ \\
\hline 70006.9 & 193 & $\begin{array}{r}1.17536 \\
10\end{array}$ & $\begin{array}{r}0.32643 \\
5\end{array}$ & $\begin{array}{r}0.60566 \\
10\end{array}$ & $\begin{array}{r}0.49439 \\
8\end{array}$ & $\begin{array}{r}0.13518 \\
5\end{array}$ \\
\hline 70003.9 & 143 & $\begin{array}{r}1.17552 \\
12\end{array}$ & $\begin{array}{r}0.32669 \\
7\end{array}$ & $\begin{array}{r}0.60534 \\
8\end{array}$ & $\begin{array}{r}0.49428 \\
8\end{array}$ & $\begin{array}{r}0.13517 \\
5\end{array}$ \\
\hline 70001.9 & 135 & $\begin{array}{r}1.17552 \\
16\end{array}$ & $\begin{array}{r}0.32669 \\
10\end{array}$ & $\begin{array}{r}0.60526 \\
11\end{array}$ & $\begin{array}{r}0.49427 \\
11\end{array}$ & $\begin{array}{r}0.13519 \\
11\end{array}$ \\
\hline
\end{tabular}

a Normalized to ${ }^{147} \mathrm{Sm} /{ }^{154} \mathrm{Sm}=0.65918$. Errors are $2 \sigma_{\text {mean }}$.

b Russ (1974).

Gadolinium isotopic ratios (Table I) have been arbitrarily normalized to $\left({ }^{156} \mathrm{Gd} /{ }^{160} \mathrm{Gd}\right)=0.9361$ to correct for mass fractionation in the spectrometer. The normalization introduces a false discrimination factor of $\frac{1}{4}\left({ }^{155} \mathrm{Gd} /{ }^{156} \mathrm{Gd}\right)_{\mathrm{T}} \sigma_{5} \psi$ per mass unit (Eugster et al., 1970b) (a quantity which will subsequently be referred to as $\beta$ ) because the ${ }^{156} \mathrm{Gd}$ reference isotope is enhanced by neutron capture. The ratio $\left({ }^{155} \mathrm{Gd} /{ }^{156} \mathrm{Gd}\right)_{\mathrm{T}}$ refers to the terrestrial ratio, $\sigma_{5}$ is the neutron capture cross section for ${ }^{155} \mathrm{Gd}$, and $\psi$ is the neutron fluence. Corrected (C) ratios for isotope $x,(x / 160)_{\mathrm{C}}$, can be calculated from the arbitrarily normalized ratios $(x / 160)_{\mathrm{N}}$ as

$$
\left(\frac{x}{160}\right)_{\mathrm{C}}=\left(\frac{x}{160}\right)_{\mathrm{N}}\left(\frac{1+n \alpha+n \beta}{1+n \alpha}\right)
$$

where $n=160-x, \alpha$ is the fractionation factor per mass unit and $\beta$ is the previously mentioned false discrimination factor. 
The correlation between $\left({ }^{157} \mathrm{Gd} /{ }^{160} \mathrm{Gd}\right)_{\mathrm{N}}$ and $\left({ }^{158} \mathrm{Gd} /{ }^{160} \mathrm{Gd}\right)_{\mathrm{N}}$ for all samples measured in this work is shown in Figure 1. The solid line is the theoretical correlation between these isotopes assuming neutron capture by Gd which initially had terrestrial isotopic abundances.

The ratios of the less abundant isotopes $\left({ }^{154} \mathrm{Gd} /{ }^{160} \mathrm{Gd}\right)_{\mathrm{C}}$ and $\left({ }^{152} \mathrm{Gd} /{ }^{160} \mathrm{Gd}\right)_{\mathrm{C}}$ are generally higher in lunar materials than in terrestrial samples. Russ (1973) suggests that some of the deviation may be due to mass interferences from $\mathrm{Sm}$ isotopes. Since ${ }^{154} \mathrm{Sm}$ and ${ }^{152} \mathrm{Sm}$ are the heaviest $\mathrm{Sm}$ isotopes, the presence of this element will not affect the more important isotopic ratios of the heavier $\mathrm{Gd}$ isotopes. In addition, Russ (1973) demonstrated that the ${ }^{152} \mathrm{Gd}$ abundance may be enriched by the reaction ${ }^{151} \mathrm{Eu}(n, \gamma){ }^{152} \mathrm{Eu}\left(\beta^{-}\right)^{152} \mathrm{Gd}$. We believe that the apparent overabundance of these light isotopes can be plausibly explained and is not a general phenomenon which affects the more critical measurements of the heavy $\mathrm{Gd}$ isotopes.

The $\mathrm{Sm}$ isotopic ratios (Table II) have been normalized to ${ }^{147} \mathrm{Sm} /{ }^{154} \mathrm{Sm}=0.65918$ to correct for mass discrimination (Russ et al., 1971). Unlike the Gd isotopes, the

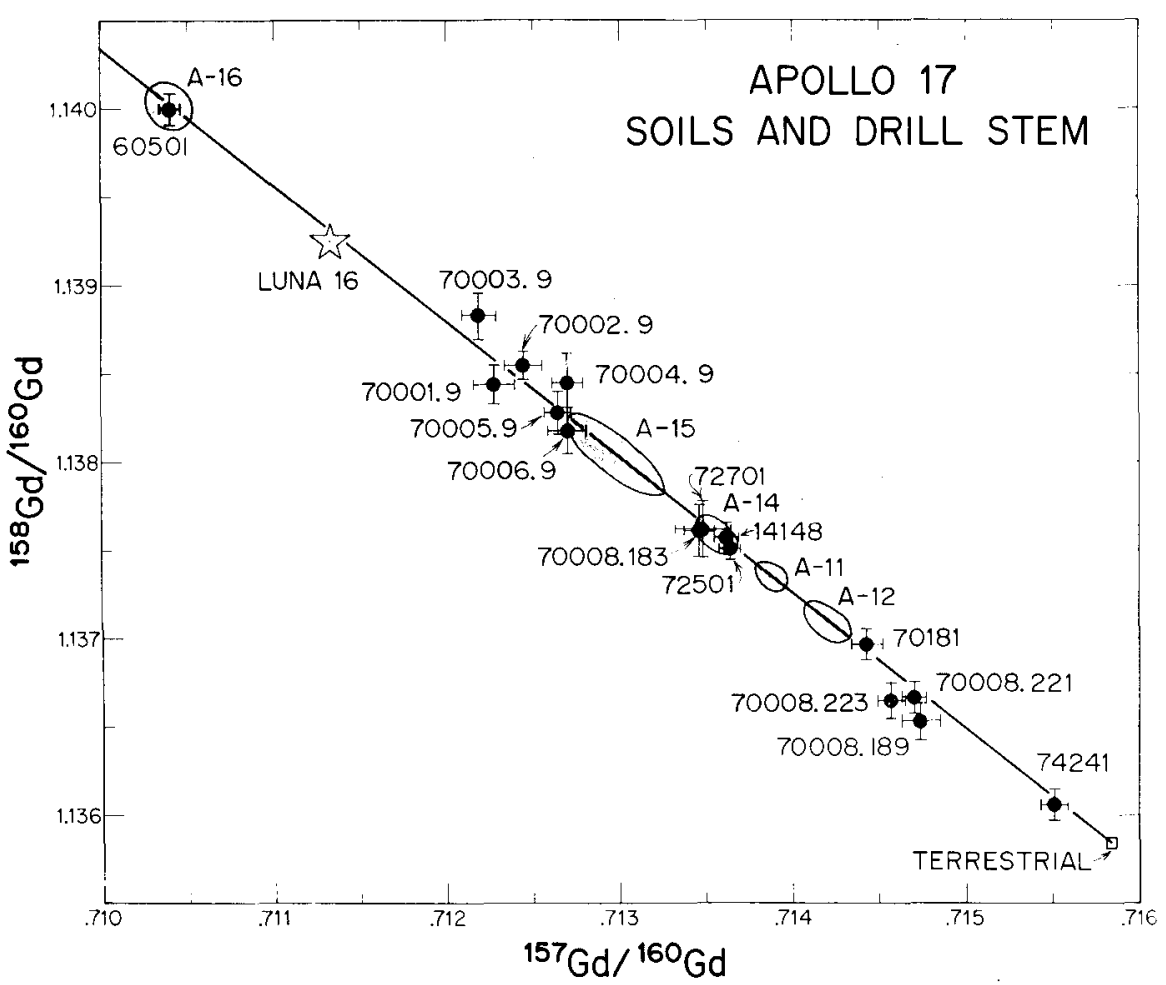

Fig. 1. ${ }^{157} \mathrm{Gd} /{ }^{160} \mathrm{Gd}$ vs ${ }^{158} \mathrm{Gd} /{ }^{160} \mathrm{Gd}$ correlation diagram. Ranges in values in surface soils from sites other than Apollo 17 are shown in outlined regions. The solid line is the theoretical correlation assuming neutron capture by materials with terrestrial isotopic abundances prior to neutron exposure. The displacement from the terrestrial value is a direct measure of the total neutron fluence received by a sample. 
TABLE III

Summary of neutron capture effects on Apollo 17 material

\begin{tabular}{|c|c|c|c|c|c|c|}
\hline Sample & $\begin{array}{l}\text { Depth or } \\
\text { location }\end{array}$ & $\left(\frac{{ }^{158} \mathrm{Gd}}{157 \mathrm{G}}\right)_{N}$ & $\left(\frac{{ }^{150} \mathrm{Sm}}{{ }^{149} \mathrm{Sm}}\right)$ & $\begin{array}{l}\sum_{\text {eff }} \\
\left(10^{-2} \mathrm{~cm}^{2} \mathrm{~g}^{-1}\right)\end{array}$ & $\begin{array}{l}\text { Fluence } \\
\left(10^{16} \mathrm{n} \mathrm{cm}^{-2}\right)\end{array}$ & $\varepsilon_{\mathrm{sm}} / \varepsilon_{\mathrm{Gd}}$ \\
\hline Terrestrial $^{\mathbf{a}}$ & & $\begin{array}{r}1.58652 \\
7\end{array}$ & $\begin{array}{r}0.53403 \\
3\end{array}$ & & & \\
\hline 14148 & Apollo 14 & $\begin{array}{l}1.59389 \\
\pm \quad 20\end{array}$ & $\begin{array}{r}0.53772 \\
\pm \quad 9\end{array}$ & 0.91 & $\begin{array}{r}2.81 \\
\pm 0.08\end{array}$ & $\begin{array}{r}0.84 \\
\pm 0.03\end{array}$ \\
\hline 60501 & Apollo 16 & $\begin{array}{r}1.60428 \\
19\end{array}$ & $\begin{array}{r}0.54046 \\
16\end{array}$ & 0.48 & $\begin{array}{l}5.60 \\
0.06\end{array}$ & $\begin{array}{l}0.61 \\
0.02\end{array}$ \\
\hline 72701 & Station 2 & $\begin{array}{r}1.59426 \\
42\end{array}$ & & 0.58 & $\begin{array}{l}2.60 \\
0.14\end{array}$ & \\
\hline 72501 & Station 2 & $\begin{array}{r}1.59377 \\
16\end{array}$ & & 0.59 & $\begin{array}{l}2.43 \\
0.06\end{array}$ & \\
\hline 74241 & $\begin{array}{l}\text { Station } 4 \\
\text { Gray Soil }\end{array}$ & $\begin{array}{r}1.58774 \\
21\end{array}$ & $\begin{array}{r}0.53469 \\
10\end{array}$ & 1.0 & $\begin{array}{l}0.48 \\
0.09\end{array}$ & $\begin{array}{l}0.91 \\
0.22\end{array}$ \\
\hline 70181 & ALSEP & $\begin{array}{r}1.59132 \\
23\end{array}$ & $\begin{array}{r}0.53628 \\
12\end{array}$ & 1.0 & $\begin{array}{l}1.88 \\
0.09\end{array}$ & $\begin{array}{l}0.79 \\
0.06\end{array}$ \\
\hline $\begin{array}{l}70008.189 \\
\text { (parent } \# 163 \text { ) }\end{array}$ & $\begin{array}{l}50 \mathrm{~g} \mathrm{~cm}^{-2} \\
(28 \mathrm{~cm})\end{array}$ & $\begin{array}{r}1.59017 \\
28\end{array}$ & & $0.95^{b}$ & $\begin{array}{l}1.37 \\
0.07\end{array}$ & \\
\hline 70008.221 & $\begin{array}{l}67 \mathrm{~g} \mathrm{~cm}^{-2} \\
(36 \mathrm{~cm})\end{array}$ & $\begin{array}{r}1.59040 \\
19\end{array}$ & & $0.95^{b}$ & $\begin{array}{l}1.50 \\
0.08\end{array}$ & \\
\hline $\begin{array}{l}70008.232 \\
\text { (parent \#209) }\end{array}$ & $\begin{array}{l}101 \mathrm{~g} \mathrm{~cm}^{-2} \\
(52 \mathrm{~cm})\end{array}$ & $\begin{array}{r}1.59057 \\
22\end{array}$ & $\begin{array}{r}0.53613 \\
11\end{array}$ & $0.95^{b}$ & $\begin{array}{l}1.56 \\
0.09\end{array}$ & $\begin{array}{l}0.85 \\
0.06\end{array}$ \\
\hline $\begin{array}{l}70008.183 \\
\text { (parent \#201) }\end{array}$ & $\begin{array}{l}126 \mathrm{~g} \mathrm{~cm}^{-2} \\
(64 \mathrm{~cm})\end{array}$ & $\begin{array}{r}1.59450 \\
29\end{array}$ & $\begin{array}{r}0.53772 \\
8\end{array}$ & $0.95^{b}$ & $\begin{array}{l}3.00 \\
0.11\end{array}$ & $\begin{array}{l}0.81 \\
0.04\end{array}$ \\
\hline $\begin{array}{l}70006.9 \\
\text { (parent } \not 019)\end{array}$ & $\begin{array}{c}180 \mathrm{~g} \mathrm{~cm}^{-2} \\
(93 \mathrm{~cm})\end{array}$ & $\begin{array}{r}1.59673 \\
30\end{array}$ & $\begin{array}{r}0.53896 \\
10\end{array}$ & 0.95 & $\begin{array}{l}3.92 \\
0.12\end{array}$ & $\begin{array}{l}0.81 \\
0.03\end{array}$ \\
\hline 70005.9 & $\begin{array}{l}252 \mathrm{~g} \mathrm{~cm}^{-2} \\
(133 \mathrm{~cm})\end{array}$ & $\begin{array}{r}1.59699 \\
24\end{array}$ & & 0.89 & $\begin{array}{l}3.96 \\
0.09\end{array}$ & \\
\hline 70004.9 & $\begin{array}{l}326 \mathrm{~g} \mathrm{~cm}^{-2} \\
(173 \mathrm{~cm})\end{array}$ & $\begin{array}{r}1.59724 \\
31\end{array}$ & & 0.93 & $\begin{array}{l}3.98 \\
0.12\end{array}$ & \\
\hline 70003.9 & $\begin{array}{l}400 \mathrm{~g} \mathrm{~cm}^{-2} \\
(213 \mathrm{~cm})\end{array}$ & $\begin{array}{r}1.59867 \\
28\end{array}$ & $\begin{array}{r}0.53967 \\
11\end{array}$ & 0.87 & $\begin{array}{l}4.55 \\
0.11\end{array}$ & $\begin{array}{l}0.78 \\
0.02\end{array}$ \\
\hline 70002.9 & $\begin{array}{l}473 \mathrm{~g} \mathrm{~cm}^{-2} \\
(253 \mathrm{~cm})\end{array}$ & $\begin{array}{r}1.59804 \\
24\end{array}$ & & 0.90 & $\begin{array}{l}4.24 \\
0.09\end{array}$ & \\
\hline 70001.9 & $\begin{array}{l}535 \mathrm{~g} \mathrm{~cm}^{-2} \\
(289 \mathrm{~cm})\end{array}$ & $\begin{array}{r}1.59801 \\
30\end{array}$ & $\begin{array}{r}0.53974 \\
19\end{array}$ & 0.88 & $\begin{array}{l}4.30 \\
0.11\end{array}$ & $\begin{array}{l}0.84 \\
0.04\end{array}$ \\
\hline
\end{tabular}

a Eugster et al. (1970b), Russ (1974).

${ }^{b}$ Assumes $\Sigma_{\text {epr }}$ is the same as 70006.9 .

c See text. 
isotopic ratio used for normalization is unaffected by neutron capture. The results presented in Table II may be used without further correction. The ratios $\left({ }^{150} \mathrm{Sm} /{ }^{154} \mathrm{Sm}\right)$ and $\left({ }^{149} \mathrm{Sm} /{ }^{154} \mathrm{Sm}\right)$ are respectively enriched and depleted due to neutron capture. The ${ }^{152} \mathrm{Sm} /{ }^{154} \mathrm{Sm}$ ratios vary from the terrestrial ratios by amounts slightly greater than the statistical uncertainty. This has been observed in other Sm isotopic determinations. It is believed to be due to mass interferences in the spectrometry and not the result of neutron capture effects (Russ et al., 1971). The ratios ${ }^{148} \mathrm{Sm} /{ }^{154} \mathrm{Sm}$ and ${ }^{144} \mathrm{Sm} /{ }^{154} \mathrm{Sm}$ agree very well with measured terrestrial values.

The parameters which are important to a discussion of the neutron fluence and the depositional history of the lunar regolith are presented in Table III. The fluence is calculated from the normalized $\left({ }^{158} \mathrm{Gd} /{ }^{157} \mathrm{Gd}\right)_{\mathrm{N}}$ ratio by the equation

$\psi=\frac{\left[\left({ }^{158} \mathrm{Gd} /{ }^{157} \mathrm{Gd}\right)_{\mathrm{N}}-\left({ }^{158} \mathrm{Gd} /{ }^{157} \mathrm{Gd}\right)_{\mathrm{T}}\right] f}{\left\langle\sigma_{157}\right\rangle\left(1-\left({ }^{158} \mathrm{Gd} /{ }^{157} \mathrm{Gd}\right)_{\mathrm{N}}\right)+\frac{1}{4}\left\langle\sigma_{155}\right\rangle\left({ }^{158} \mathrm{Gd} /{ }^{157} \mathrm{Gd}\right)_{\mathrm{T}}\left({ }^{155} \mathrm{Gd} /{ }^{156} \mathrm{Gd}\right)_{\mathrm{T}}}$,

where $\left\langle\sigma_{155}\right\rangle=0.24\left\langle\sigma_{157}\right\rangle$.

The 'average' neutron capture cross sections $(\langle\sigma\rangle)$ is a weighted average, the weighting factor being the neutron energy spectrum for $E<0.18 \mathrm{eV}$ neutrons calculated from LCH (1972). The fraction of total neutrons with energies less than $0.18 \mathrm{eV}$ captured by ${ }^{157} \mathrm{Gd}(f)$ was calculated by Russ (1974) using data from $\mathrm{LCH}$. The neutron energy spectrum and hence $\langle\sigma\rangle$ and $f$, are functions of the chemical composition of the moderating material. Dependence upon the composition is characterized by the effective macroscopic capture cross section $\left(\Sigma_{\text {eff }}\right)$ which is a strong function of the concentrations of elements with large thermal neutron capture sections, i.e., $\mathrm{Ti}$ and $\mathrm{Fe}$ (see Appendix I).

The $\varepsilon_{\mathrm{Sm}} / \varepsilon_{\mathrm{Gd}}$ values in Table III are the ratios of the ${ }^{149} \mathrm{Sm}$ to ${ }^{157} \mathrm{Gd}$ capture rates. The quantity $\varepsilon$ is calculated from experimental results as

$$
\varepsilon=\frac{(D / T)_{\mathrm{M}}-(D / T)_{\mathrm{T}}}{1+(D / T)_{\mathrm{M}}}
$$

$(D / T)_{\mathrm{M}}$ and $(D / T)_{\mathrm{T}}$ being, respectively, the measured and terrestrial ratios of the daughter isotope and the target isotope from which it was produced. Since this parameter is the small difference of two large numbers, the uncertainties are rather large.

\subsection{Elemental CONCENTRATION}

The abundances of $\mathrm{K}, \mathrm{Rb}, \mathrm{Sr}$ and $\mathrm{Ba}$ are presented in Table IV. Abundances of $\mathrm{Rb}$, and to a lesser extent, $\mathrm{K}$ and $\mathrm{Ba}$ are characteristic of the apparent source of the soils. Material from deep in the core is similar to the soils from near the North Massif (stations 6 and 9) or near the Sculptured Hills (station 8) (PET, 1974) which contain considerable material from the massifs (Duncan et al., 1974; Brunfelt et al., 1974; Heiken and McKay, 1974). There is a general increase in the abundance of $\mathrm{K}, \mathrm{Rb}$ and $\mathrm{Ba}$ with increasing depth. The four most shallow samples have abundances which are more characteristic of the soils from the valley floor (stations 1 and 5) (PET, 1974) 
TABLE IV

Elemental abundances in Apollo 17 deep drill stem

\begin{tabular}{lllll}
\hline & $\begin{array}{l}\mathrm{K} \\
(\mathrm{ppm})\end{array}$ & $\begin{array}{l}\mathrm{Rb} \\
(\mathrm{ppm})\end{array}$ & $\begin{array}{l}\mathrm{Sr} \\
(\mathrm{ppm})\end{array}$ & $\begin{array}{l}\mathrm{Ba} \\
(\mathrm{ppm})\end{array}$ \\
\hline 70008.189 & & & & \\
70008.221 & 650 & 1.20 & 191 & 96 \\
70008.232 & 580 & 1.05 & 153 & 89 \\
70008.183 & 670 & 1.14 & 175 & 92 \\
70006.9 & 720 & 1.55 & 183 & 99 \\
70005.9 & 870 & 2.34 & 186 & 121 \\
70004.9 & 820 & 1.74 & 159 & 104 \\
70003.9 & 800 & 1.93 & 157 & 116 \\
70002.9 & 980 & 2.47 & 165 & 140 \\
70001.9 & 960 & 2.70 & 133 & 193 \\
74242.8 & 900 & 2.26 & 172 & 117 \\
(fine grained) & 750 & 0.75 & 161 & 177 \\
\hline
\end{tabular}

a Philpotts et al. (1973).

which consist largely of comminuted basalt (Duncan et al., 1974; Brunfelt et al., 1974, Heiken and McKay, 1974). There appears to be a sharp distinction between the chemical composition of material deeper than $180 \mathrm{~g} \mathrm{~cm}^{-2}$ (70006) and that which is shallower than $100 \mathrm{~g} \mathrm{~cm}^{-2}$ (70008.221). Chemical abundances in 70008.183 from $125 \mathrm{~g} \mathrm{~cm}^{-2}$ are generally intermediate between the compositions of soils in the shallow sections and those from the deep sections of the drill stem. The distinction is most obvious in the $\mathrm{Rb}$ abundances, but it is also demonstrated by the abundances of $\mathrm{K}$ and $\mathrm{Ba}$. For purposes of comparison we have included in Table IV the results of analyses on the fine grain portions of sample 74242, a soil sample consisting entirely of basaltic fragments (Philpotts et al., 1973).

\section{The Lunar Neutron Energy Spectrum}

The ratio $\varepsilon_{S m} / \varepsilon_{G d}$ is presented in Table III. LCH (1972) predicted a functional dependence between the energy spectrum and the concentration of elements with appreciable neutron capture cross sections in the moderating material. The ratio $\varepsilon_{\mathrm{Sm}} / \varepsilon_{\mathrm{Gd}}$ decreases as the effective cross section of the material $\left(\Sigma_{\text {eff }}\right)$ decreases. Russ et al. (1972) and Russ (1973) plotted measured values of $\varepsilon_{\mathrm{Sm}} / \varepsilon_{\mathrm{Gd}}$ vs $\Sigma_{\mathrm{eff}}$, calculated from the chemical composition of the irradiated soils. While the results qualitatively verified the $\mathrm{LCH}$ predictions, the absolute magnitudes of $\varepsilon_{\mathrm{Sm}} / \varepsilon_{\mathrm{Gd}}$ were greater than the theoretical calculations. The lunar neutron spectrum apparently has a relatively greater high energy component than was theoretically predicted. Figure 2 corresponds to the figure previously shown by Russ et al. (1972) and Russ (1973), with the Apollo 17 results added. Only samples for which the chemical compositions have been measured directly are included in Figure 2, i.e., no inferred values of $\Sigma_{\text {eff }}$ have been included. The present results are in accord with the conclusions of the previous work. 
LCH calculations of neutron flux have indicated that the low energy portion of the neutron energy spectrum is independent of depth. The Lunar Neutron Probe Experiment (LNPE) by Burnett et al. (1974) measured the Cd ratio at two depths in the regolith and showed a shift in the energy spectrum with depth. The $\mathrm{Cd}$ ratio was greater at $373 \mathrm{~g} \mathrm{~cm}^{-2}$ than at $180 \mathrm{~g} \mathrm{~cm}^{-2}$, indicating a shift in the neutron energy spectrum to lower energies with increasing depth. Woolum et al. (1975) studied the differences between the calculated energy spectrum of $\mathrm{LCH}$ and the properties of the energy spectrum as measured by the LNPE and the isotopic measurements. They concluded that the divergence may be an indication that the ${ }^{158} \mathrm{Gd}$ production rate as calculated by LCH is too large by about a factor of two. If this interpretation is correct, all time related parameters which have been published and those presented here would have to be recalculated (Eugster et al., 1970; Burnett et al., 1971; Russ et al., 1972; Russ,

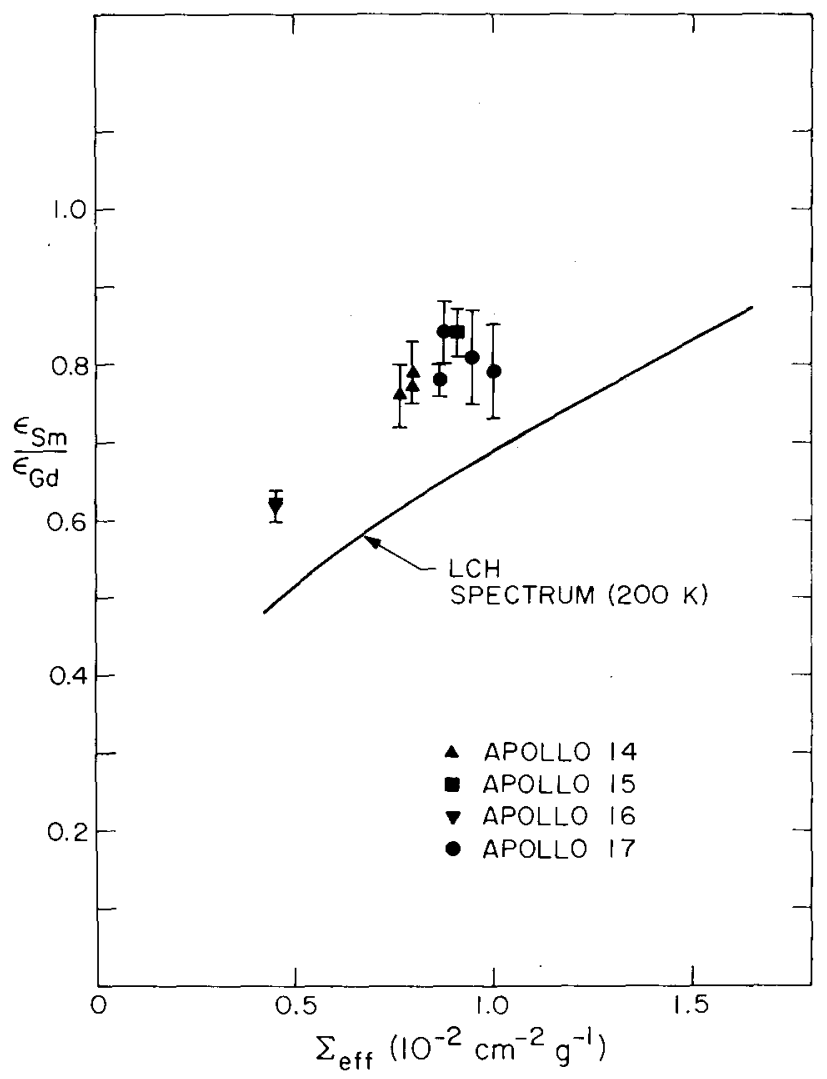

Fig. 2. Functional dependence between the relative production rates of ${ }^{150} \mathrm{Sm}$ and ${ }^{158} \mathrm{Gd}\left(\varepsilon_{\mathrm{Sm}} / \varepsilon_{\mathrm{Gd}}\right)$ and the effective macroscopic capture cross section ( $\left.\Sigma_{\text {eff }}\right)$. The ratio $\varepsilon_{\mathrm{Sm}} / \varepsilon_{\mathrm{Gd}}$ is dependent on the neutron energy spectrum. Decreasing values of this ratio reflect shifts in the spectrum to lower energies. The offset between measured values and theoretical values shows that the lunar neutron spectrum is shifted to somewhat higher energies relative to the theoretical spectrum predicted by LCH (1972). 
1973). However, the general conclusions and ideas which have been espoused would still be valid within the context in which they were presented.

Our measurements of $\varepsilon_{\mathrm{Sm}} / \varepsilon_{\mathrm{Gd}}$ in samples from different depths do not manifest a change in the energy spectrum with depth. The uncertainty of the ratios may be sufficiently large to mask the effect.

We have taken advantage of the relationship between $\varepsilon_{\mathrm{Sm}} / \varepsilon_{\mathrm{Gd}}$ and $\Sigma_{\text {eff }}$ to infer the latter from measurements of the former. In this way we are able to calculate fluences in samples (70008) where we lacked sufficient chemical analyses to calculate $\Sigma_{\text {eff }}$, and thus $\langle\sigma\rangle$ and $f$, directly.

\section{The Neutron Fluence and the Neutron Flux}

Lingenfelter et al. (1972), Armstrong and Alsmiller (1971), and Kornblum et al. (1973) have calculated the flux of neutrons as a function of depth in materials of lunar composition. The calculations by LCH gave particular consideration to the low energy portion of the spectrum which is important for neutron capture by Gd and Sm. This calculation supercedes the earlier work of Lingenfelter et al. (1961) which was done prior to the detailed chemical abundance data obtained from the Apollo missions. The theoretical neutron flux calculated by LCH (1972) will be used throughout this paper.* The depth dependence of the lunar neutron flux in the low energy region was measured directly by the Lunar Neutron Probe Experiment during the Apollo 17 mission (Burnett and Woolum, 1974). There is very good agreement between the depth dependence measured by the LNPE and that which was calculated by LCH.

Figure 3 shows the low energy neutron flux $(<0.18 \mathrm{eV})$, which is directly proportional to the ${ }^{158} \mathrm{Gd}$ production rate as a function of depth in the outer few meters of the Moon (also see tabulated values in the Appendix). The salient features of the curve are the low flux in the top few $\mathrm{g} \mathrm{cm}^{-2}$, a sharp increase in the rate to a maximum value at a depth of about $160 \mathrm{~g} \mathrm{~cm}^{-2}$, and a subsequent decrease with increasing depths. The increase in the flux is about an order of magnitude between $10 \mathrm{~g} \mathrm{~cm}^{-2}$ and the maximum at $160 \mathrm{~g} \mathrm{~cm}^{-2}$.

The decrease with depth beyond the peak is sufficiently rapid that $90 \%$ of the total neutrons are produced in the top $500 \mathrm{~g} \mathrm{~cm}^{-2}$ of the lunar soil. We shall henceforth refer to this top $500 \mathrm{~g} \mathrm{~cm}^{-2}$ as the nuclear active zone.

If we consider a thick slab of unirradiated material at the surface of the Moon, as time increases the neutron fluence will increase at each depth depending on the neutron flux at that depth. Assuming the material in this slab to be unmixed by impacts, the observed fluence curve will be the same as the flux curve (Figure 3) times the duration of the exposure.

Russ et al. (1972) determined the total neutron fluence as a function of depth down

* We have included an appendix which provides a detailed explanation of the method used to calculate the neutron flux as a function of depth in lunar materials. For convenience, the appendix includes a compilation of information to allow the $\mathrm{LCH}$ neutron flux to be calculated directly without reference to the original sources. 
to $400 \mathrm{~g} \mathrm{~cm}^{-2}$ in the lunar soil at the Apollo 15 site. These experiments yielded a remarkably smooth variation of fluence with depth. In addition to the regularity of the fluence, it demonstrated a functional dependence which was very similar to the flux curve calculated by LCH (1972) (Figure 3). The result suggested that this sampling of $2.4 \mathrm{~m}$ of regolith at the Appenine front was emplaced about $0.5 \mathrm{AE}$ ago and has subsequently remained undisturbed.

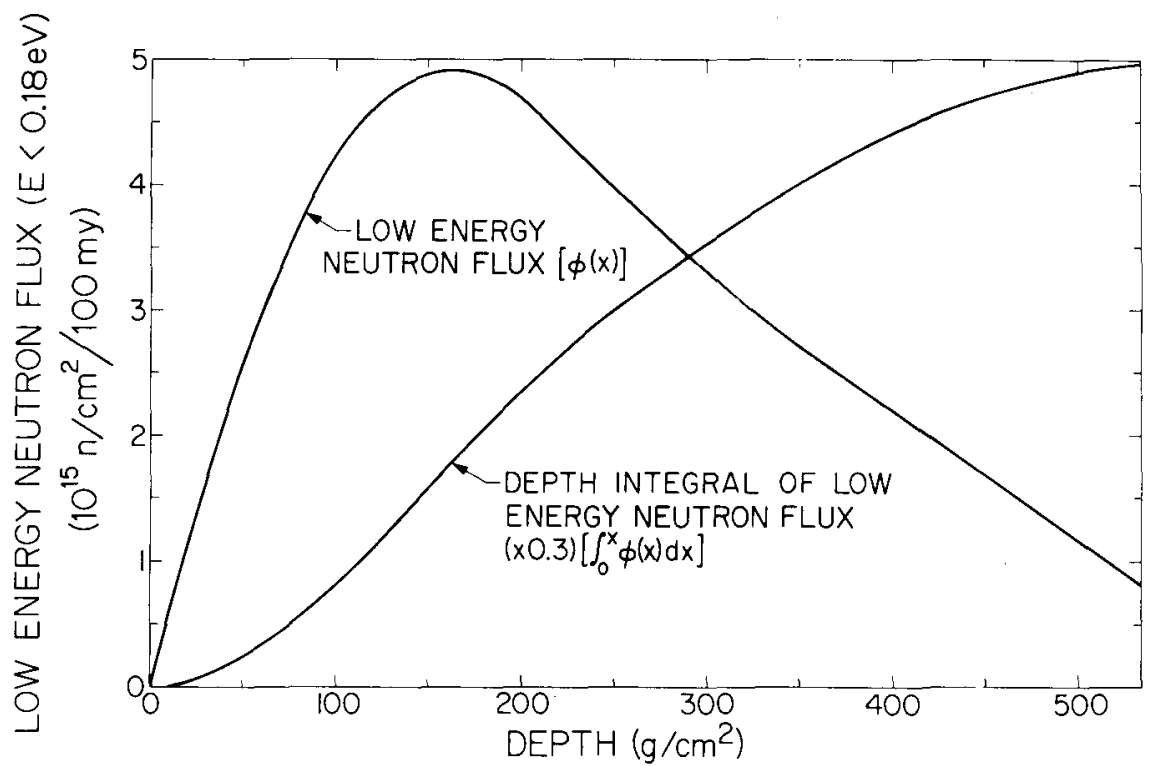

Fig. 3. Functional dependence between the low energy neutron flux $(E<0.18 \mathrm{eV})$, which is directly proportional to the ${ }^{158} \mathrm{Gd}$ production rate, and depth in the lunar soil (assuming chemical composition like materials in the Apollo 17 deep drill stem). This curve is the form of the fluence profile which would result from extended periods of static irradiation of an initially unirradiated material. The integral of the neutron flux curve is also shown. This is the fluence profile which would result from the accretion of unirradiated soils at a constant rate.

Another model which is useful to consider is the accretion of lunar soil at a uniform rate in a local topographic depression. Consider that a steady rain of debris slowly fills the depression so that each stratigraphic layer, as a result of burial, effectively moves from the surface to the present depth. If the depositing material were isotopically normal (i.e., unirradiated) and if the depression is still being filled at the time of sampling, then the functional dependence between the observed fluence and depth will be identical to the integral of the neutron flux curve as shown in Figure 3; it increases more slowly than the simple flux curve, effectively saturating at a depth of about $500 \mathrm{~g} \mathrm{~cm}^{-2}$. At greater depths there is little change in the integral because of the greatly diminished neutron flux. A suggestion of such a case was found in a study of the Apollo 16 drill string by Russ (1973); however, the data showed significant complications so that no clear-cut interpretation could be made. 


\section{The Apollo 17 Deep Drill Stem}

The fluence in the three meters of material sampled in the Taurus Littrow valley provides the striking profile shown in Figure 4a. In the lower part of the drill stem we analyzed six samples from six individual strata and the three major stratigraphic intervals identified by the PET (1974) and found them to have nearly identical fluences. The magnitudes of the normalized * fluence in these six samples are the largest which has been measured on the Moon except at the Luna 16 site (Russ, 1972). Three samples, from depths of $50-100 \mathrm{~g} \mathrm{~cm}^{-2}$ also have nearly identical fluences. The magnitude of the neutron fluences in these shallow samples are the lowest which have been measured in lunar soils except for samples from the rims of deep craters. Material taken at a depth intermediate to the two fluence plateaus $\left(125 \mathrm{~g} \mathrm{~cm}^{-2}\right)$ has had an irradiation history intermediate to the extremes of the core. A surface sample taken three meters away from the deep drill core is included in Figure 4. Fluence in this soil is slightly larger than in the three samples extracted from the shallow portions of the drill stem.

The variation of ${ }^{150} \mathrm{Sm} /{ }^{149} \mathrm{Sm}$ in selected samples from the core confirms the fluence profile calculated from the Gd isotopes. The results of the Sm measurements are shown in Figure 4b.

The sigmoidal shape of the variation of fluence with depth is qualitatively suggestive of the integral of the flux curve (Figure 3 ) corresponding to accretion at a constant rate. Attempts to fit the curve to a simple accretion model demonstrate the fallacy of this observation. Figure 3 shows that a uniformly accreting soil generates a fluence which increases to a depth of about $500 \mathrm{~g} \mathrm{~cm}^{-2}$, at greater depths the fluence becomes essentially constant. The fluence in the Apollo 17 drill stem reaches a plateau at a relatively modest depth of $180 \mathrm{~g} \mathrm{~cm}^{-2}$. Hence, a simple accretionary model cannot provide an adequate description of the fluence profile in this vertical section of the lunar regolith.

In general the rate of sediment accumulation in a basin may not be constant but may decrease as the basin is filled. As a limiting case this process can be described by sedimentation at a constant rate followed by a quiescent period of negligible accumulation. This two stage model is a sum of the integral of the neutron flux weighted by the inverse of the rate of accretion and the flux weighted by the time since accretion stopped. Inspection of Figure 3 shows that this combination of models will yield a neutron fluence which effectively saturates at depths shallower than $500 \mathrm{~g} \mathrm{~cm}^{-2}$ and which might more adequately describe the observed data.

In the next section we will give the equations which describe the above models and evaluate the extent to which the data may be described by them.

* The absolute magnitude of the neutron flux is a function of the chemical composition of the moderating material. For the purposes of comparison between sites it is necessary to normalize the measured fluence to irradiation in material with a standard chemical composition. A value of $\Sigma_{\text {eff }}=9.25 \times$ $\times 10^{-2} \mathrm{~cm}^{2} \mathrm{~g}^{-1}$ was chosen as standard composition because it was originally used by LCH to calculate their depth integrated flux (Russ, 1974). See appendix I for details on normalization procedure. 


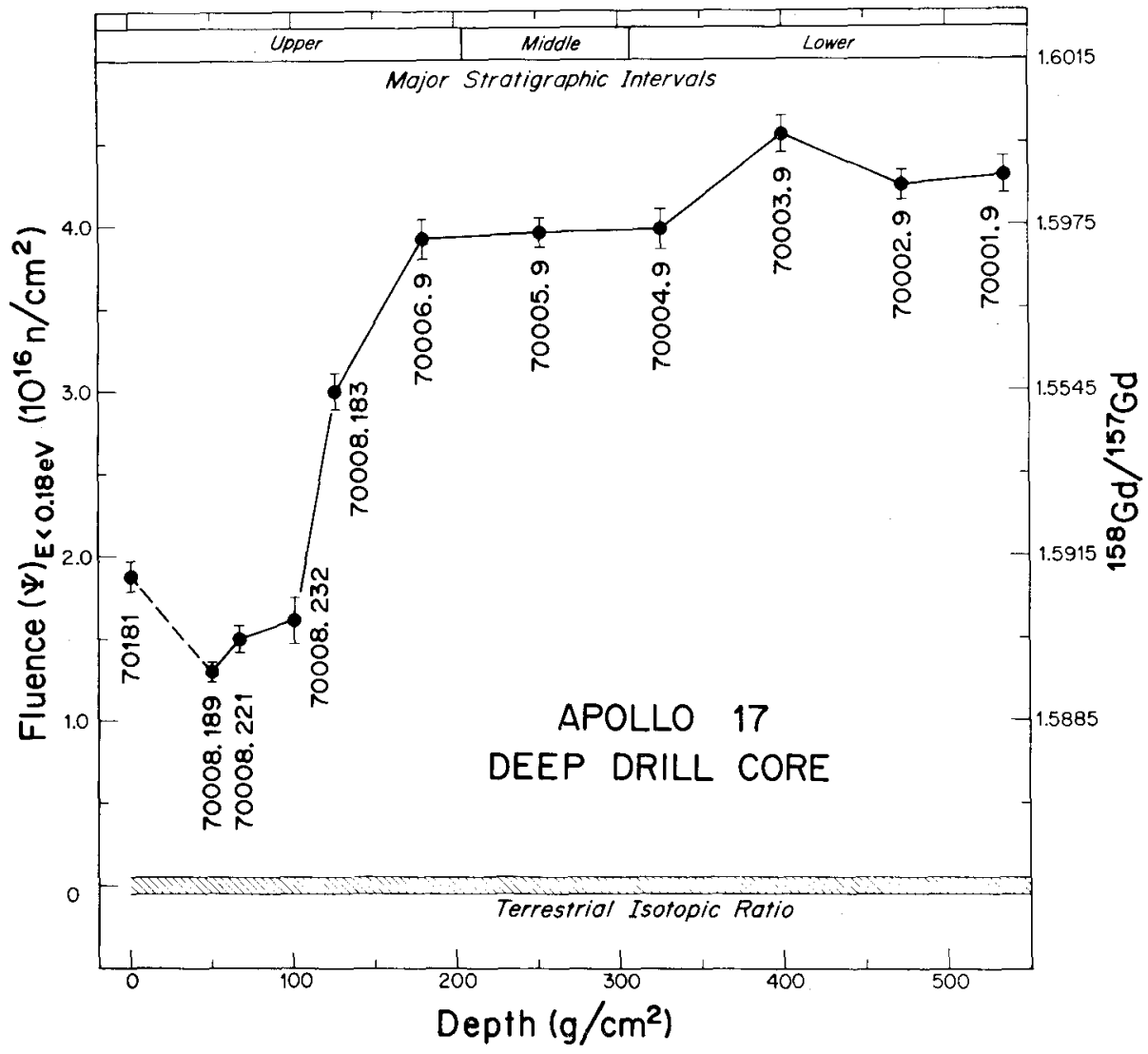

Fig. 4a. The neutron fluence profile, measured by ${ }^{158} \mathrm{Gd} /{ }^{157} \mathrm{Gd}$, as a function of depth in the Apollo 17 deep drill stem. Note the thick section of nearly constant high fluence (70001-70006) which extends through the three major stratigraphic intervals defined by the Preliminary Examination Team (1974), and the thin section of materials with nearly constant low fluence in the shallow sections (70008.232-70008.189). Sample 70008.183 is transitional between the two constant fluence sections both in its location and in the intermediate nature of its neutron fluence. Sample 70181 was taken from the surface, three meters from the location of the deep drill stem.

\subsection{Consideration of SIMPLE MODELS AND THE APOLlo 17 DEEP DRILL CORE}

It is unrealistic to discuss models in terms of soils which have had no previous neutron irradiation. Measurements of fluence in material from all sites and from depths ranging from the surface to three meters have failed to yield a sample with evidence of no neutron exposure. Therefore the fluence in any sample must involve the superposition of the fluence due to irradiation prior to deposition $\left(\psi_{0}\right)$ and a term which describes the functional dependence between the fluence and the present vertical displacement from the surface. Decoupling these two contributions is one of the difficulties in interpreting the measured fluences in terms of dynamic processes occurring in the lunar regolith. These models have been discussed in previous papers by Eugster et al.(1970b), Russ et al. (1972), and Russ (1973). 


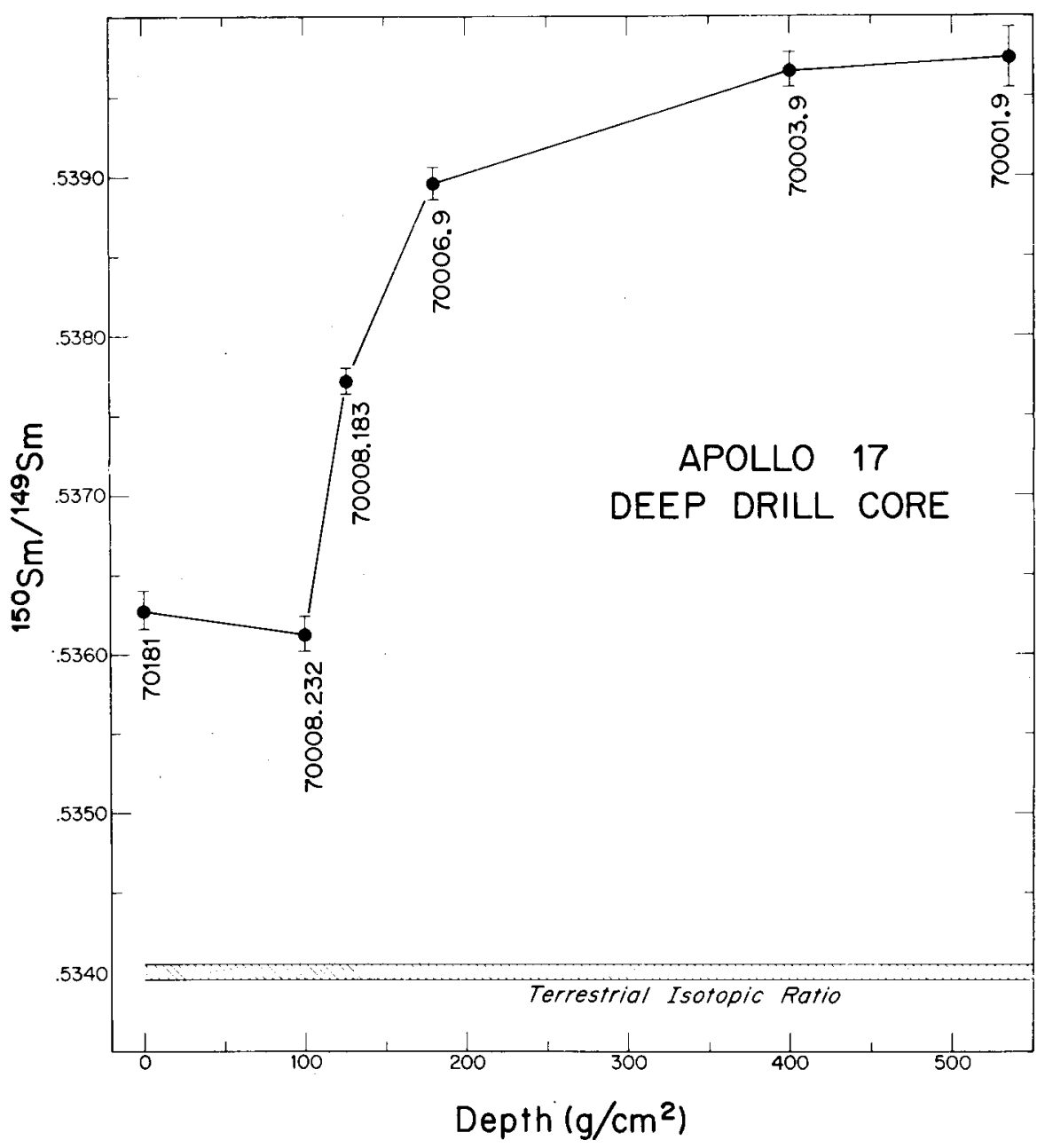

Fig. 4b. The variation of ${ }^{150} \mathrm{Sm} /{ }^{149} \mathrm{Sm}$ confirms the depth dependence of neutron fluence inferred from the $\mathrm{Gd}$ isotopes.

Static irradiation: Equation (1) describes the fluence in a model of undisturbed irradiation for an extended period of time as

$$
\psi(D)=\psi_{0}(D)+T \Phi(D) ;
$$

$\psi_{0}(D)$ is the fluence of the layer at $D$ due to predepositional irradiation, $T$ is the duration of the static exposure, and $\Phi(D)$ is the neutron flux at depth $D$. Variability in $\psi_{0}(D)$ can cause wide fluctuations above the flux curve.

Steady accretion: An analogous equation may be written for a soil which is accreting at a constant rate. If $V$ is the constant rate of accretion, then the time which a layer spends at depths between $x$ and $x+\mathrm{d} x$ is $\mathrm{d} x / V$. This yields an equation of the 
form

$$
\psi(D)=\psi_{0}(D)+\frac{1}{V} \int_{0}^{D} \Phi(\eta) \mathrm{d} \eta .
$$

The functional dependence between fluence and depth is expressed by the integral of the neutron flux; the magnitude of that term is inversely proportional to the rate of accretion $(V)$, i.e., the more rapid the accretion the smaller the effect.

Steady erosion: Erosion at a steady rate produces a fluence profile which is the complement of the case of accreting soil. The maximum fluence occurs at the surface and decreases to very low values at depth. Like the accreting soil, the absolute magnitude of the fluence is a function of the inverse of the rate of the process $(V)$-i.e.,

$$
\psi(D)=\psi_{0}(D)+\frac{1}{V} \int_{D}^{\infty} \Phi(\eta) \mathrm{d} \eta .
$$

Accretion and static irradiation: A model which considers the deposition of the soil as three separate episodes: (1) irradiation prior to deposition, (2) accretion at a constant rate $(V)$ followed by (3) a period $(T)$ of undisturbed irradiation yields a fluence profile which is described by a combination of Equations (1) and (2) as

$$
\psi(D)=\psi_{0}(D)+\frac{1}{V} \int_{0}^{D} \Phi(\eta) \mathrm{d} \eta+T \Phi(D) .
$$

Uniform mixing: Another limiting model can be formulated by assuming the outer layers of the regolith to be rapidly well mixed from the surface down to a depth $L$; we will call this zone the mixed layer. The magnitude of the dose is the product of the depth averaged flux $\left(\bar{P}_{L} \equiv \int_{0}^{L} \Phi(\eta) \mathrm{d} \eta / L\right)$ and the period of irradiation in the mixed zone $(T)$ : i.e.,

$$
\psi(D)=T \bar{P}_{L}, \quad L>D>0 .
$$

If the time and the depth parameters are combined as the rate of mixing $\left(\dot{R}_{L}=L / T\right)$, Equation (5) can be restated as

$$
\psi(D)=\frac{\int_{0}^{L} \Phi(\eta) \mathrm{d} \eta}{R_{L}} .
$$

Predepositional doses in the previous models $\left(\psi_{0}\right)$ can be interpreted by Equation (5). In this case the sedimenting materials are derived from a fictive zone of deep mixing which was irradiated for a time much longer than the period of sedimentation. Accretion and static irradiation with continuous surface mixing: A slightly more sophisticated model of turnover can be formulated by considering mixing to be the result of two processes; mixing in the shallow portion of the regolith to depths $l$ 
(less than $1 \mathrm{~m}$ ) and deep mixing to a depth $L$ which stirs the soil to depths of several meters. The former process must have a high probability of occurrence within the time period considered while the probability of deep mixing is much less and has a recurrence time which is comparable with the time of deposition of layers down to several meters. This model provides expressions for fluence in the surface mixing layer in terms of parameters derived from models of the depositional history of the site.

Consider a model of uniform accretion with velocity $V$ such that the material down to depth $l$ is subject to continuous shallow mixing. As new material is added to the mixed layer an equal amount is assumed to flow out of the bottom of the mixed layer at depth $l$ and become buried. The rate of change of the fluence in the shallow mixed layer with time $(\tau)$ is expressed by

$$
\frac{\mathrm{d} \psi(D, \tau)}{\mathrm{d} \tau}=\frac{V}{l}\left[\psi_{0}(\tau)-\psi(\tau, D)\right]+\bar{P}_{l}, \quad 0 \leqslant D \leqslant l .
$$

If we take $\psi_{0}(\tau)$ to be constant or slowly varying, then for times large compared to the mean residence time of the mixed layer $(\tau \gg l / V)$, the fluence in material within the mixed layer is given by

$$
\psi(D, \tau) \cong l / V \bar{P}_{l}+\psi_{0}(\tau) .
$$

Materials below the shallow mixing zone have a neutron fluence which is produced by simple accretion at a constant rate (Equation (2)).

If accretion is followed by a period of static irradiation $(T)$ with no stirring below the mixed layer, then the fluence in soils below the mixed zone is given by Equation (4) and within the mixed zone by

$$
\psi(D, \tau)=(l / V+T) \bar{P}_{l}+\psi_{0}(\tau) .
$$

Modeling: Attempts were first made to fit the data with a simple accretionary model (Equation (2)), assuming that the fluence $\psi_{0}(D)$ due to pre-irradiation was constant throughout the core. In this case the difference in fluence for two sample points $D_{1}$ and $D_{2}$ can be used to determine the rate of accretion from

$$
V=\frac{\int_{D_{2}}^{D_{1}} \Phi(\eta) \mathrm{d} \eta}{\psi\left(D_{1}\right)-\psi\left(D_{2}\right)} .
$$

Model profiles were generated using Equation (2) and the calculated parameters. Figure 5 shows the results of this curve fitting using the deepest sample as the deep limit and samples from depth $A$ or from depth $B$ as the shallow limit. Inspection of Figure 5 shows that such models give fluences at depths between $150-300 \mathrm{~g} \mathrm{~cm}^{-2}$ which are considerably less than measured at these depths; clearly this model is not descriptive of the depositional processes at the site of the Apollo 17 deep drill stem.

A model of accretion followed by static irradiation provides a better fit to the data. The fitting procedure for this model was again done by assuming $\psi_{0}(D)$ to be constant 


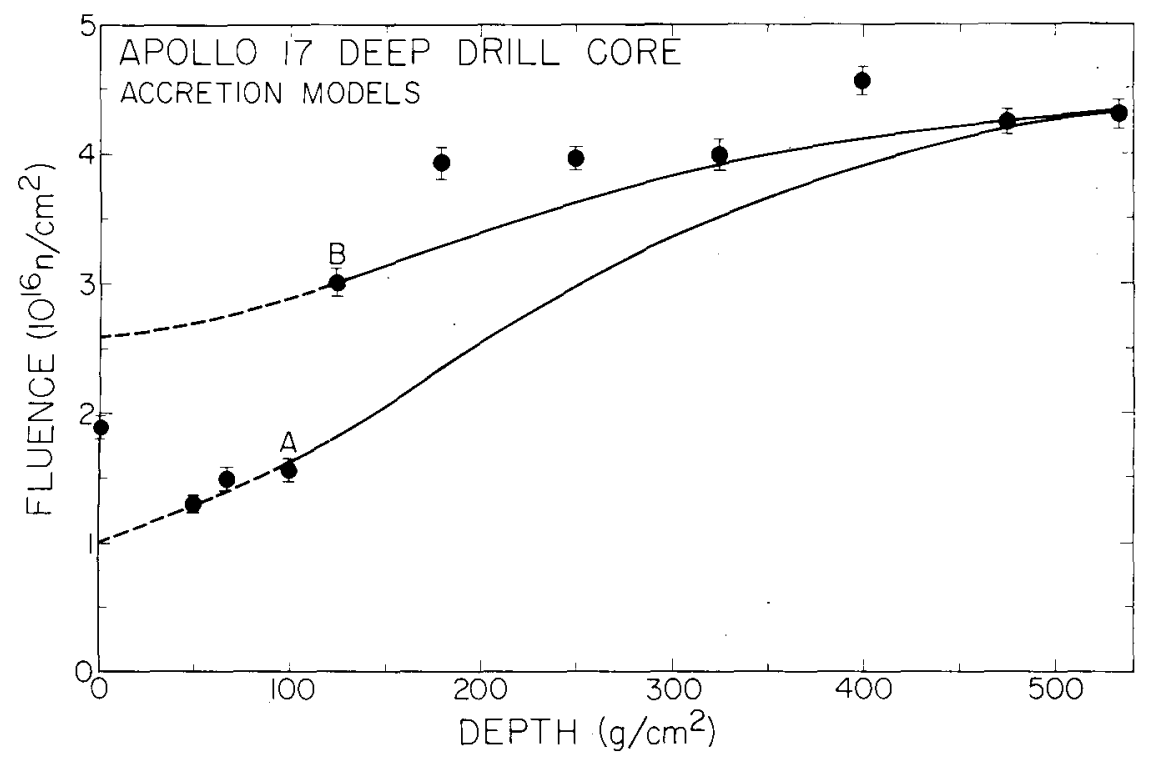

Fig. 5. Attempts to fit a model of accretion at a constant rate to the neutron fluence profile in the Apollo 17 deep drill stem. Parameters $\left(\psi_{0}\right.$ and $\left.V\right)$ were calculated using measured fluences from the deepest sample and a shallow sample ( $A$ or $B$ ). Note the failure of simple accretion models to predict high measured fluences in materials from the midsections of the drill stem.

for the entire length of the core. Values for the rate of accretion $(V)$, the period of irradiation $(T)$, and the predepositional fluence $\left(\psi_{0}\right)$ were calculated using Equation (4) and the measured fluence in a shallow sample, a sample from intermediate depths, and a deep sample.

Figure 6 shows fits to the data. Model $A$ is a good fit for most of the data points. The model describes a soil accreted from completely unirradiated material $\left(\psi_{0}=0\right)$ at a rate of $43 \mathrm{~g} \mathrm{~cm}^{-2} / 100 \mathrm{~m} . \mathrm{y}$. ( $2 \mathrm{~mm} / \mathrm{m} . \mathrm{y}$.), followed by $460 \mathrm{~m} . \mathrm{y}$. of undisturbed irradiation. Note, in particular, that data points at 62 and $100 \mathrm{~g} \mathrm{~cm}^{-2}$ fall below curve $A$. A slight variation in parameters, still assuming $\psi_{0} \equiv 0$, would offset the model fluence slightly so that it goes through or slightly below all the data points deeper than $100 \mathrm{~g} \mathrm{~cm}^{-2}$. However, the shallow data point at $100 \mathrm{~g} \mathrm{~cm}^{-2}$ will still be below the curve. In general, small deviations of data from the model can be rationalized by variations of $\psi_{0}$ from the assumed constant value. However, in this specific case we have assumed $\psi_{0}=0$ and it is impossible to explain data points which fall below the model fluence by variation of $\psi_{0}$. It follows that model $A$ has a fatal flaw and thus cannot be completely descriptive of the processes which have produced the neutron exposure in the Apollo 17 deep drill stem.

The inadequacy in model $A$ can be eliminated by assuming that the top $100 \mathrm{~g} \mathrm{~cm}^{-2}$ of the drill stem was recently mixed. The result is shown in Figure 6 as model B. Mixing produces a constant fluence in the top $100 \mathrm{~g} \mathrm{~cm}^{-2}$ of the profile. The magnitude of the constant fluence is an average of the fluence in the top $100 \mathrm{~g} \mathrm{~cm}^{-2}$ of model $A$, 


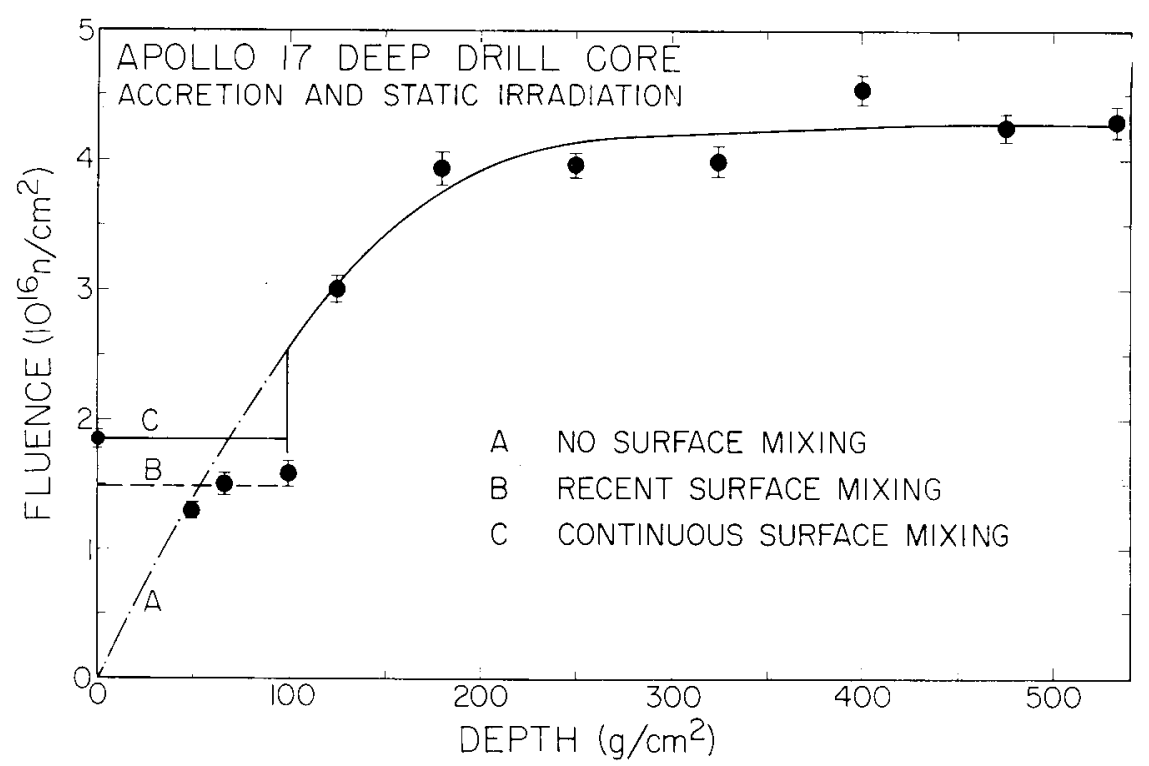

Fig. 6. Fits to the fluence profile in the Apollo 17 deep drill stem for models of accretion at a constant rate followed by a period of static irradiation. Case $A$ was fit by calculating the unknown parameters $\left(\psi_{0}, T, V\right)$ using three measured fluences with Equation (4). Note the large discrepancy between the model and the measured fluence at $100 \mathrm{~g} \mathrm{~cm}^{-2}$. Model $B$ assumes the top $100 \mathrm{~g} \mathrm{~cm}^{-2}$ to have been recently well mixed, otherwise it is identical to model $A$. This model adequately fits the data. Model $C$ assumes a continuous mixed zone down to $100 \mathrm{~g} \mathrm{~cm}^{-2}$ in conjunction with the model of accretion and static irradiation. Extended residence times in the mixed layer produce fluences near the surface which are greater than measured. All of these models require a continuous source of unirradiated material.

the profile in the remaining depths is the same for both models. Model $B$ furnishes an adequate description of the data.

Alternatively, we could consider a model of accretion followed by static irradiation in which surface mixing is a continuing process for the entire history of the drill stem. The appropriate equations for the model are given by (9) for the mixed surface layer and (4) which describes the fluence profile below the mixed zone. We have attempted to fit the data to the model assuming the mixed layer to be $100 \mathrm{~g} \mathrm{~cm}^{-2}$ thick $(l=100 \mathrm{~g}$ $\left.\mathrm{cm}^{-2}\right)$. Three parameters $\left(\psi_{0}, T, V\right)$ were calculated using three data points, one from the mixed zone (excluding the surface), one from an intermediate depth, and one from material deep in the core. Solution of the appropriate equations provides negative values for one of the parameters. Such values are physically meaningless in the context of this model. We cannot obtain a fit to this model by assuming that materials from the entire length of the deep drill stem have had similar irradiation histories.

Model $C$ in Figure 6 shows an attempt to fit the continuous mixing model to the data assuming unirradiated source material $\left(\psi_{0}=0\right)$. Note that the model provides the same representation of the fluence profile below the mixed layer as models $A$ and $B$. However, the model fluence within the mixed layer is significantly higher than the 
fluence in the mixed layer in model $B$, the latter being a good representation of the data. The higher fluence in the continuous mixing model (model $C$ ) is due to the longer residence time in the surface layer $(l / V+T)$ relative to the residence time $(l / 2 V+T)$ for the model which attributes mixing to a single recent event (model $B$ ). As we mentioned previously, models which assume an unirradiated source of materials cannot explain data points which fall below the model by variations in $\psi_{0}$. Therefore, this model cannot be a good description of the depositional history of the Apollo 17 deep drill stem.

The simplest continuous mixing model which will fit the data must assume the soils in the mixed surface layer to have been unirradiated prior to deposition, while the deeper parts of the core were accreted from materials which had been uniformly irradiated. The predepositional dose $\left(\psi_{0}\right)$ which is calculated for the deep material is $6 \times 10^{15} \mathrm{n} \mathrm{cm}^{-2}$, the rate of accretion is $42 \mathrm{~g} \mathrm{~cm}^{-2} / 10^{8} \mathrm{yr}$ and the period of static irradiation is 353 m.y.

General consequences of the in situ irradiation models: All models involving in situ irradiation which approximate the observations require accretion over a period of about $1.2 \mathrm{AE}$ at a rate of about $45 \mathrm{~g} \mathrm{~cm}^{-2} / 10^{8} \mathrm{yr}(\sim 2.3 \mathrm{~mm} / \mathrm{m} . \mathrm{y}$.) followed by $350-450$ m.y. with no subsequent disturbances deeper than $100 \mathrm{~g} \mathrm{~cm}^{-2}$. Of the models which we have considered, the only ones which adequately describe the fluence profile in the Apollo 17 deep drill core require the surface layer to have had a distinct history compared to the remainder of the core. The best fits to these models all require a continuous accretion of this vertical section of the regolith from a source of lightly irradiated material $\left(\psi_{0}<6 \times 10^{15} \mathrm{n} \mathrm{cm}^{-2}\right)$.

The only plausible source of lightly irradiated material is from depth. It is unreasonable to postulate that the core was accreted over a period of more than an AE exclusively from material excavated from deep craters or from a rapidly eroding slope on the massif. Consider a more general case in which a single deep cratering event deposits a blanket of unirradiated material adjacent to the site which will eventually be sampled by the Apollo 17 deep drill stem. A steady rate of erosion of this initially unirradiated material into the drill stem site would provide a source of material from which to accrete the core. The rate of erosion must be very fast because material must spend a limited period of time in the nuclear active zone to maintain a low fluence. We can estimate a rate of erosion which is compatible with a lightly irradiated source from Equation (3) $\left(D=0, \psi_{0}=0\right)$. If $5 \times 10^{15} \mathrm{n} \mathrm{cm}^{-2}$ is considered the maximum predepositional fluence which is compatible with the model, the calculated rate of erosion is $350 \mathrm{~g} \mathrm{~cm}^{-2}$, about an order of magnitude greater than the rate of accretion indicated by the model fit. Thus, this also is an unacceptable source of material.

We cannot propose a realistic source of lightly irradiated material with which to accrete the core. As a result, we consider models of in situ irradiation to be an unsatisfactory description of the depositional history of the Apollo 17 deep drill core.

Models of rapid accumulation: The models which were discussed above imply a history for the Apollo 17 drill stem which extends back well over an AE. A diametrically opposite model considers the core to have undergone essentially no in situ 
irradiation. If well mixed material were deposited rapidly in times which are relatively recent there would be no functional relationship between the present depth and the fluence; the neutron fluence would be strictly a function of the irradiation history prior to emplacement of the samples. This suggests a model for the Apollo 17 deep drill core of two distinct layers each deposited rapidly from materials with characteristic isotopic ratios. The similarity of isotopic ratios observed in six samples from the bottom two meters implies similar predepositional irradiation histories for the material which comprises this section. In the same manner, the isotopic ratios in three samples between $50 \mathrm{~g} \mathrm{~cm}^{-2}$ and $100 \mathrm{~g} \mathrm{~cm}^{-2}$ could be taken to reflect similar irradiation histories for soils from this portion of the stem but quite distinct from the deep samples. The single sample with distinct isotopic abundances $\left(125 \mathrm{~g} \mathrm{~cm}^{-2}\right)$ is most plausibly considered an admixture of material from the bottom of the upper layer with material from the top of the lower layer, the mixing perhaps being attributable to disturbance at the time of deposition of the top layer.

Consequences of the rapid accumulation model: In the context of this model the three meters of material in the Apollo 17 deep drill stem must represent a very young layer since it shows no structure due to in situ irradiation. We have attempted to establish limits on the age of the deep slab of material by two methods (1) in situ irradiation of a medium with a uniform predepositional dose $\left(\psi_{0}(D)\right)$ would generate a peak at $\sim 180 \mathrm{~g} \mathrm{~cm}^{-2}$ and a decreasing fluence between $180 \mathrm{~g} \mathrm{~cm}^{-2}$ and $325 \mathrm{~g} \mathrm{~cm}^{-2}$ An irradiation period of 100 m.y. would produce a decrease of $0.2 \times 10^{16} \mathrm{n} \mathrm{cm}^{-2}$ within the interval. Such a disparity is not observed in the data and is slightly larger than the maximum the error limits would allow. (2) Another estimate may be made by assuming that the dispersion in all the data below $180 \mathrm{~g} \mathrm{~cm}^{-2}$ is due to initial variations in the predepositional fluence in this zone. The data point at $400 \mathrm{~g} \mathrm{~cm}^{-2}$ is displaced by $0.40 \times 10^{16} \mathrm{n} \mathrm{cm}^{-2}$ from the mean value of the deep zone. If we take twice this value as the dispersion and assume that any sample in this region started with a predepositional fluence less than the mean value by $2 \times 0.40 \times 10^{16} \mathrm{n} \mathrm{cm}^{-2}$ and resided at the depth of maximum neutron flux, the maximum time of in situ irradiation would be 160 m.y.

We conclude from these considerations that in the context of a rapid accumulation model, the deepest material in the core was emplaced in the last 100-200 m.y. This interpretation considers the layers of material at the bottom of the Apollo 17 core to be significantly younger than materials extracted from similar depths at other lunar sites. Russ et al. (1972) and Russ (1973) place limits on the times of deposition of deep materials from the Apollo 15 and Apollo 16 deep drill cores which range from $\sim 400$ m.y. to $\sim 1$ AE.

The rapid accumulation model requires that the layer of material at the bottom of the drill stem have a high predepositional fluence of $\psi_{0}(D) \approx 4 \times 10^{16} \mathrm{n} \mathrm{cm}^{-2}$. Only one sample, the Luna 16 material (Russ, 1972), has had a normalized neutron fluence of this magnitude. A large quantity of material with an extended irradiation history is required to describe the Apollo 17 fluence profile by a two slab model.

The principal objections to a two slab model rest in (1) the young age of these layers, 
and (2) the large magnitude of the predepositional fluences. We will examine other properties of the materials from the core to try to determine the credibility of this model.

\section{2. 'AVERAGE' DEPTHS OF IRRADIATION}

Eugster et al. (1970) pointed out that the flux of high energy particles decreases as a function of the depth in the lunar regolith, in contrast to the low energy neutron flux which rises to a maximum at depths well below the surface and then decreases with depth (Figure 3). A ratio of the high energy particle flux to the low energy neutron flux decreases with increasing depth to depths below the peak in the low energy flux curve and then becomes constant with further increase in depth. Consequently, a ratio of the products of irradiation by high energy particles and the products of low energy neutron capture should manifest the 'average' depth at which a sample received most of its exposure. Rare gases produced by spallation reactions serve as monitors of the high energy particle flux and the ${ }^{158} \mathrm{Gd} /{ }^{157} \mathrm{Gd}$ ratio monitor the low energy neutron flux. We have considered the change as a function of depths of the ratio of ${ }^{126} \mathrm{Xe}_{\mathrm{sp}}$ / $(\mathrm{Ba}+1.65 \mathrm{Ce})^{*}$ (hereafter simply referred to as $\left.{ }^{126} \mathrm{Xe}_{\mathrm{sp}}\right)$ to $\psi_{\text {norm }}$ in the Apollo 15 and Apollo 17 deep drill stems. ${ }^{126} \mathrm{Xe}$ was used as the spallogenic gas because it is an isotope which has a large spallation component and is retained relatively well.

Pepin et al. (1974) and Bogard et al. (1973) have measured ${ }^{126} \mathrm{Xe}_{\mathrm{sp}}$ in the Apollo 15 deep drill core. We have preferentially used the data of Pepin et al. (1974), since they selected their samples to correspond with those which were used by Russ et al. (1972) for the neutron fluence measurements. Rare gas measurements in the surface soil (15041) is from Bogard et al. (1973) in the absence of data on this sample from Pepin et al. (1974).

The ${ }^{158} \mathrm{Gd} /{ }^{157} \mathrm{Gd}$ measurements in the Apollo 15 deep drill core appear to closely reflect the depth dependence of the low energy neutron flux in the lunar regolith indicating an extended period of undisturbed irradiation (Russ et al., 1972). Pepin et al. (1974) noted that ${ }^{126} \mathrm{Xe}_{\mathrm{sp}}$ apparently manifests the anticipated depth dependence of the high energy particle flux and thus substantiates the depositional history inferred from the Gd isotopes. Figure 7 shows the depth profile of this ratio in the Apollo 15 drill stem; it decreases monotonically down to a depth of $200 \mathrm{~g} \mathrm{~cm}^{-2}$ and remains essentially constant below that depth. The ratio ${ }^{126} \mathrm{Xe}_{\mathrm{sp}} / \psi$ illustrates the depth dependence which was predicted by Eugster et al. (1970).

Eberhardt et al. (1974) have measured the abundance of ${ }^{126} \mathrm{Xe}_{\mathrm{sp}}$ as a function of depth in the Apollo 17 deep drill stem. Based upon these results they presented two models for the depositional history of the core which are conceptually similar to the models which we have presented in the previous sections. The interpretation of their results were inhibited because of the necessity to infer the abundance of target elements

* It is necessary to normalize for the abundance of target elements since the concentration of these trace elements is likely to vary considerably between samples (Huneke et al., 1972). 


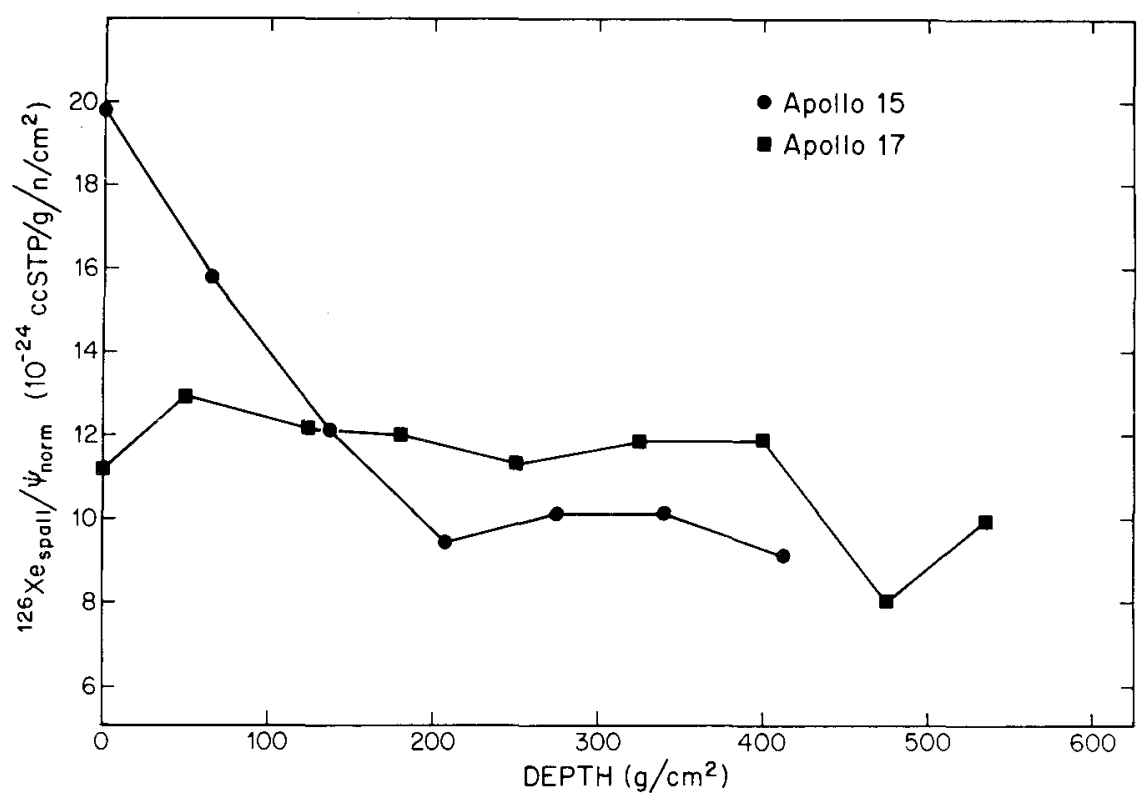

Fig. 7. Variation of the ratio of spallogenic ${ }^{126} \mathrm{Xe}$ (Pepin et al., 1974; Eberhardt et al., 1974) (normalized to abundances of $\mathrm{Ba}+1.65 \mathrm{Ce}$ ) to the low energy neutron fluence (normalized to standard chemical composition) as a function of depth in the Apollo 15 and Apollo 17 deep drill stems. The monotonic decrease of the ratio in the shallow sections of the core reflects differences in the depth dependence of the high energy particle flux and the low energy neutron flux at these depths; the constant ratio below $200 \mathrm{~g} \mathrm{~cm}^{-2}$ reflects similarities in the depth dependence at greater depths. The profile is compatible with a model of static irradiation as suggested by Russ et al. (1972).

The uniformity of the ratio ${ }^{126} \mathrm{Xe}_{\mathrm{sp}} / \psi_{\text {norm }}$ through most of the Apollo 17 drill stem suggests that the core was accreted entirely from material which has been well mixed to depths greater than the nuclear active zone. The profile is compatible with a model of rapid accumulation but not with models of in situ irradiation.

to normalize their ${ }^{126} \mathrm{Xe}_{\mathrm{sp}}$ abundances. We have renormalized the ${ }^{126} \mathrm{Xe}_{\mathrm{sp}}$ abundances in the Apollo 17 core using the $\mathrm{Ba}$ abundances reported in Table IV and the REE abundances reported by Helmke et al. (1973). The renormalized concentrations are given in Table $\mathrm{V}$.

Most of the renormalized rare gas data correlates very closely with the variation of neutron fluences in the core. The only sample analyzed for rare gases from the low fluence part of the drill stem also contains small quantities of spallogenic ${ }^{126} \mathrm{Xe}_{\mathrm{sp}}$. The remainder of the core contains greater amounts of the spallogenic gas in direct correspondence to the magnitude of the neutron fluence. An exception is sample 70002 from a depth of $475 \mathrm{~g} \mathrm{~cm}^{-2}$. The neutron fluence in this sample is similar in magnitude to five other samples which define the high fluence plateau, however, the normalized ${ }^{126} \mathrm{Xe}_{\mathrm{sp}}$ in 70002 is considerably less than in the other five samples. The discrepancy appears to be due to unusually high concentrations of $\mathrm{Ba}$ and REE which result in the low normalized ${ }^{126} \mathrm{Xe}_{\mathrm{sp}}$ abundances. This is perhaps attributable to a false normalization since the gas data and the elemental abundances were not measured 
TABLE V

Spallation Xenon-126 and fluence ratios

\begin{tabular}{lll} 
Sample & $\begin{array}{l}\left.{ }^{126} \mathrm{Xe}_{\mathrm{sp}} /(\mathrm{Ba}+1.65 \mathrm{Ce})\right]^{\mathrm{a}, \mathrm{b}} \\
\left(\mathrm{cc} \mathrm{STP} \mathrm{g}^{-1}\right)\end{array}$ & $\begin{array}{l}\left({ }^{126} \mathrm{Xe}_{\mathrm{sp}} / \psi_{\text {norm }}\right) \\
\left(10^{-\varepsilon 4} \mathrm{cc} \mathrm{STP} \mathrm{g}^{-1} \mathrm{n}^{-1}\right.\end{array}$ \\
\hline 70001.9 & $4.0 \times 10^{-7}$ & 9.9 \\
70002.9 & $3.3 \times 10^{-7}$ & 8.0 \\
70003.9 & $4.9 \times 10^{-7}$ & 11.9 \\
70004.9 & $4.7 \times 10^{-7}$ & 11.8 \\
70005.9 & $4.3 \times 10^{-7}$ & 12.0 \\
70006.9 & $4.9 \times 10^{-7}$ & 12.1 \\
70008.183 & $3.6 \times 10^{-7}$ & 11.2 \\
70008.189 & $1.8 \times 10^{-7}$ & \\
70181 & $2.35 \times 10^{-7}$ & \\
\hline a Rare gas data from Eberhardt et al. (1974) & \\
h Rare earth abundances from Helmke et al. $(1973), \mathrm{Ba}$ abundances from \\
Table IV, this paper.
\end{tabular}

on splits of the same sample. This emphasizes the potential errors in making comparisons between properties measured on different samples taken from about the same depth.

The ${ }^{126} \mathrm{Xe}_{\mathrm{sp}} / \psi$ vs depth in the Apollo 17 deep drill stem is plotted in Figure 7. The depth profile is striking; the ratio is for practical purposes constant throughout the core, with a mean value of $11.6 \times 10^{-24} \mathrm{cSTP}\left(\mathrm{g} \mathrm{n} \mathrm{cm}^{-2}\right)^{-1}$ and a standard deviation of $\sim 8 \%$ (excluding 70002). A constant ratio as a function of depth is indicative of a uniformly well mixed regolith. The most general circumstance which would produce a uniform ${ }^{126} \mathrm{Xe}_{\mathrm{sp}} / \psi$ ratio and a non-uniform neutron fluence is the accumulation of the core from sources which have been well mixed to any depth below the peak in the low energy neutron flux $\left(\sim 160 \mathrm{~g} \mathrm{~cm}^{-2}\right)$. Such materials would have constant values of the ${ }^{126} \mathrm{Xe}_{\mathrm{sp}} / \psi$ ratio independent of depth of mixing but neutron fluences which are approximately inversely proportional to the depth of mixing. If this is the case, the magnitude of the ratio in the Apollo 17 drill stem is merely the ratio of the average of the two particle fluxes in the nuclear active zone.

Extended periods of static irradiation produce variations in the ratio of ${ }^{126} \mathrm{Xe}_{\mathrm{sp}} / \psi_{\text {norm }}$ like those seen in the Apollo 15 core. This is clearly not the case for the Apollo 17 deep drill stem and the previously discussed models of in situ irradiation are incompatible with these observations. The essentially constant value of the ratio throughout the section of the regolith from the Taurus Littrow valley is compatible with the model of rapid accretion.

\subsection{Particle track ReCORd}

Crozaz et al. (1974) determined the particle track densities in six samples taken from throughout the 70008 section of the deep drill stem. Track densities decrease regularly as a function of increasing depth in the stem. They postulated that the tracks in these 
grains resulted exclusively from in situ irradiation by galactic cosmic rays and that this upper slab of material has not been disturbed since it was emplaced. The model age of emplacement for this top layer based upon track densities was $\sim 10$ m.y. Our model which yielded an upper limit on the age of emplacement of 100-200 m.y. based upon the low energy neutron fluence is compatible with the track data. The interpretation of the track record is incompatible with those models of in situ irradiation for which the materials at the base of stem 70008 had been emplaced for at least 360 m.y.

In addition to particles with very low track densities, Crozaz et al. (1974) found that $2 \%$ of the particles in the bottom sections of the 70008 had high track densities. It appears that the bottom section of the core is composed of two components, one which has had an extensive exposure and one which has had a very limited exposure to the galactic cosmic ray flux. This is similar to our interpretation of the neutron fluence in sample 70008.189 from the bottom of this section of the drill stem. We attributed the intermediate neutron fluence in this sample to a mixture of materials which have had extensive exposure to neutrons with those which have had a history of limited neutron exposure.

\subsection{Chemical and Physical PRoperties}

The Preliminary Examination Team (1974) identified three major stratigraphic intervals in the Apollo 17 deep drill stem, based mainly on the relative abundance of coarse grained $(>1 \mathrm{~mm})$ and fine grained $(<1 \mathrm{~mm})$ fragments and the lithic character of the coarser fragments. We have identified the boundaries of these three stratigraphic intervals on the neutron fluence profile in Figure 4a. It is clear that there is no correspondence between the neutron fluence and the stratigraphic intervals defined by the PET. We will attempt to correlate the irradiation characteristics with the physical and chemical properties of the core to show that there is some justification for redefining the major stratigraphic intervals in the deep drill stem. Our interpretations are somewhat hampered by the lack of consistent sets of observations which extend throughout the entire length of the core. As a result we have had to compare similar properties within the core based upon different types of observations.

Physical properties: Fine grained, well sorted material comprises the major portion of the deep part of the core (PET, 1973). These are characteristics which imply an extensive reworking by 'gardening' processes during an extended history in the regolith. One of the primary criteria for the classification of major stratigraphic intervals by the PET is the relative abundance of coarse grained and fine grained fragments. The ratio of the weight of $<1 \mathrm{~mm}$ fragments to the weight of $>1 \mathrm{~mm}$ fragments (hereafter called the fragment size ratio) ranges from 10 to 30 in materials from $70002-$ 70004 (Nagle, 1974). The fragment size ratio in 70005 (defined as the middle major stratigraphic interval by PET) is 100 (Nagle, 1974). We feel that the similarity between the chemical and irradiation properties suggests that the lower and middle major stratigraphic intervals as identified by the PET are better defined as a single major layer, hereafter referred to as the deep stratigraphic interval. 
In contrast to the newly defined deep stratigraphic interval, there is a shallow interval, extending from depths shallower than $50 \mathrm{~g} \mathrm{~cm}^{-2}$ to $100 \mathrm{~g} \mathrm{~cm}^{-2}$, which has properties indicating a limited history in the regolith. Materials from this section contain an extreme paucity of agglutinates (Heiken and McKay, 1974), a low fragment ratio of unity (Nagle, 1974), low galactic cosmic ray track densities (Crozaz et al., 1974) and relatively small quantities of solar wind gases (Eberhardt et al., 1974).

Component materials: The compositional delineation of materials in the core appears to substantiate our definition of boundaries of major stratigraphic regions in the core. The major element (Helmke et al., 1973) and trace element chemistry (Table IV) in material from the deep layer is similar to soils from stations 8 and 9 which contain varying quantities of non-mare components, presumably debris from the Sculptured Hills and the North Massif (Duncan et al., 1974; Brunfelt et al., 1974; Heiken and McKay, 1974). We estimate that the soils from the deep layer contain $\sim 35 \%$ non-mare component using the chemical mixing model of Brunfelt et al. (1974). The trace element content in soils from the shallow layer (Table IV) are akin to the elemental abundances in soils from stations 1 and 5 which are largely comminuted mare basalt. Petrographic studies on the $90-150 \mu \mathrm{m}$ size grains show the shallow section of the core to be composed largely of comminuted basalt and black and orange glass spheres (Heiken and McKay, 1974) in agreement with the inferences from the trace element data.

The transition zone: We have discussed the $\mathrm{Gd}$ isotopes, the spallation gases, and the particle track density data in materials from the bottom of 70008 and concluded that these properties are consistent with a mixture of highly irradiated material (as is found in the deep stratigraphic interval) and lightly irradiated material (similar to that in the shallow stratigraphic interval). The compositional and physical properties support an interpretation which identifies the materials from the bottom of 70008 as an admixture of soils from the two major stratigraphic intervals. (1) Materials from the bottom of 70008 have agglutinate contents (Heiken and McKay, 1974) intermediate to the extremes represented by the soils from shallow intervals and those assumed for 'mature' soils from the deep interval. (2) The trace element abundances in Table IV are the only chemical data which exists for materials over the entire length of the core. The abundances of these elements in sample 70008.183 from $125 \mathrm{~g} \mathrm{~cm}^{-2}$ are intermediate to the abundances in materials from the shallow layer and the deep layer. Note particularly $\mathrm{Rb}$ which has a concentration of $\sim 1.1 \mathrm{ppm}$ in the shallow materials, $1.55 \mathrm{ppm}$ in 70008.183 and $\sim 2.2 \mathrm{ppm}$ in the deep materials.

The abundance and lithic type of coarse fragments in sample $70006\left(180 \mathrm{~g} \mathrm{~cm}^{-2}\right)$ suggests that the transition zone extends through this depth, despite the similarity between the compositional and irradiation properties of the fine grained materials from this depth and those from the deep layer. Sample 70006 has a fragment size ratio of unity (Nagle, 1974) which indicates an abundance of coarse grain fragments similar to the shallow stratigraphic layer but in contradistinction to the grain size distribution in the deep sections of the core. The major element abundances in fine grained material from sample 70006 (Helmke et al., 1974) are virtually identical to 
those in materials from the deep section of the core. However; the coarse grained component is comprised mostly of vuggy basalt fragments (Nagle, 1973) similar to the materials in the shallow sections of the core.

Probably the two components at $180 \mathrm{~g} \mathrm{~cm}^{-2}$ in the transition zone can be clearly delinetated according to size; the coarse grained fragments from the shallow interval and the fine grained components from the deep interval. The fine grained materials from $125 \mathrm{~g} \mathrm{~cm}^{-2}$ have properties which suggest a 50-50 mixture of materials from the two major sections of the core.

Conclusions: We conclude from the preceding discussion that the Apollo 17 deep drill stem should be divided into three major stratigraphic intervals: (1) a shallow interval extending from $50 \mathrm{~g} \mathrm{~cm}^{-2}$ through $100 \mathrm{~g} \mathrm{~cm}^{-2}$ (we cannot identity a shallow boundary to this inverval), (2) a deep interval which includes materials from $250 \mathrm{~g} \mathrm{~cm}^{-2}$ through $535 \mathrm{~g} \mathrm{~cm}^{-2}$, and (3) a transition zone containing mixtures of soils from the two extreme intervals which is represented by materials from $125 \mathrm{~g} \mathrm{~cm}^{-2}$ and $180 \mathrm{~g}$ $\mathrm{cm}^{-2}$.

\subsection{SOURCES OF MATERIAL For THE APOLLO 17 DEEP DRILL STEM}

The lithic composition, grain size distribution and the location of the sampling site in the ejecta blanket of the central crater cluster suggest that material in the shallow stratigraphic interval consists mostly of ejecta from nearby deep craters. Such a source is compatible with lightly irradiated material, highly irradiated surface material being diluted with unirradiated material excavated from depths by the cratering event. The craters in the central cluster region or Camelot crater are sufficiently deep to provide the source of lightly irradiated material which comprises the top portion of the deep drill stem.

In the context of the two slab model the bottom two meters of the Apollo 17 drill stem was rapidly accreted from sources of material with fluences of about $4 \times 10^{16} n$ $\mathrm{cm}^{-2}$. This is nearly twice the value of the normalized average fluence in surface and near surface soils (Figure 8a). Near surface soils are an improbable source from which to accumulate the bottom two meters of the Apollo 17 deep drill core. It is equally improbable that materials excavated from great depths could be a source of soils with fluences of this magnitude, as the lowest fluences in the regolith (Figure 8a) are impact debris from deep excavations.

Figure $8 \mathrm{~b}$ is a histogram of the normalized fluence in materials taken from depths greater than $100 \mathrm{~g} \mathrm{~cm}^{-2}$. It is clear that the neutron fluence in materials from these depths are distinctly greater than in near surface soils or in soils from great depths. Excavation from depths greater than $\approx 100 \mathrm{~g} \mathrm{~cm}^{-2}$ down to $500 \mathrm{~g} \mathrm{~cm}^{-2}$ is a likely source of material for the accretion of the bottom two meters of the Apollo 17 deep drill stem.

\subsection{Conclusions}

Our consideration of the properties of materials from the Apollo 17 deep drill stem leads us to the following conclusions concerning this sampling of the lunar regolith. 


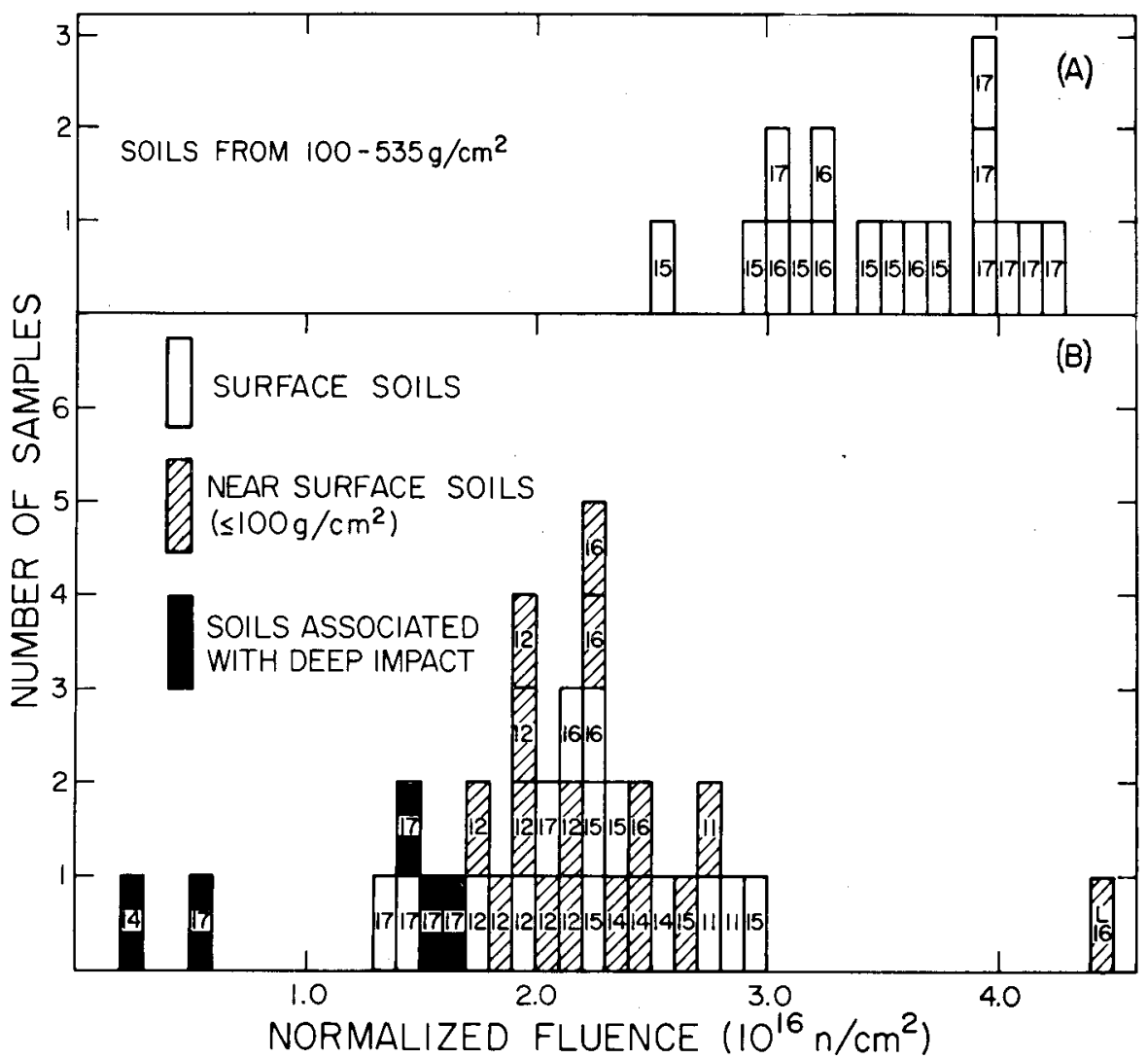

Fig. 8. Histograms of fluences in the lunar regolith (normalized to an arbitrary standard chemical composition). Figure 8 a includes all soils taken from the top $100 \mathrm{~g} \mathrm{~cm}^{-2}$. The fluences in these materials define a well mixed surface layer with an average neutron fluence of $2.3 \times 10^{16} \mathrm{n} \mathrm{cm}^{-2}$. Figure $8 \mathrm{~b}$ includes all soils taken from depths between 100 and $535 \mathrm{~g} \mathrm{~cm}^{-2}$. These define a zone which has an average fluence of $3.5 \times 10^{16} \mathrm{n} \mathrm{cm}^{-2}$. The closed boxes in $8 \mathrm{a}$ are impact debris from fresh deep craters. We infer from the low fluence in these soils that materials at great depths are very lightly irradiated. The histograms apparently reflect a general stratification of neutrons which transcends specific lunar localities. The near surface materials from each site have a narrower dispersion than the distribution of all the surface soils, presumably reflecting the local effects of specific processes.

The entire length of the core was deposited rapidly in relatively recent times. Our best estimate places an upper limit of 100-200 m.y. on the age of emplacement of the material at the bottom of the core. This limit makes these layers considerably younger than the deep core taken at the Apollo 15 site.

Despite the obvious evidence of a complex depositional history indicated by the many stratigraphic units, the entire length of the core can be considered as though it were formed from two sources of material, each with a rather narrowly defined range of chemical, physical and isotopic properties.

Soils from the shallow stratigraphic interval of the core are well mixed, immature 
materials, predominantly comminuted basalt. The grain size distribution, the small neutron dose and properties which reflect relative surface exposures indicate that these soils were recently excavated from considerable depths, and are probably debris from Camelot crater or the central cluster of craters, all of which lie in close proximity to the sampling site.

The deep stratigraphic interval of the core was formed from heavily irradiated, well mixed, mature regolith which contains a large non-mare component. A relatively extensive neutron exposure history leads us to guess that it was accreted from well mixed materials excavated from depths between $100 \mathrm{~g} \mathrm{~cm}^{-2}$ and $500 \mathrm{~g} \mathrm{~cm}^{-2}$. This layer of material is not readily associated with a specific local event, but could be the result of several rather young events. A transitional zone which is a mixture of material from the two major intervals includes samples from $125 \mathrm{~g} \mathrm{~cm}^{-2}$ and $180 \mathrm{~g} \mathrm{~cm}^{-2}$. The coarse grained component of the transition zone probably consists largely of materials similar to those found in the shallow layer. However, the fine grained component has properties which suggest it is a mixture of materials from the two stratigraphic intervals. The fraction of fine grained material from the two contributing sources grades from about $50-50$ at $125 \mathrm{~g} \mathrm{~cm}^{-2}$ to nearly all material similar to that found in the deep stratigraphic interval at $180 \mathrm{~g} \mathrm{~cm}^{-2}$. This admixture of materials may result from the physical disturbances associated with emplacement of the shallow section on top of the deep slab of material.

The proximity to the steep slopes of the North and South Massifs would lead one to expect downslope mass transport to be a factor in the formation of regolith at this site. The presence of various quantities of non-mare component implied by the chemistry of the deep section of the core bears out this expectation. The high neutron fluence makes it impossible that large amounts of massif material form a dominant provenance for these deposits from the valley.

\section{The Statistical Nature of the Fluence in the Lunar Regolith}

Previous studies of neutron fluences have emphasized model calculations in attempting to correlate neutron fluences in soils from a specific region to the depositional history of the regolith at that particular location. This approach provides insight into the mechanisms of deposition at a specific site but has limited applicability to understanding the general nature of lunar sedimentation. The primary driving force involved in sedimenting lunar materials is the impacting of extralunar bodies and the secondary impacts which result from these events. Since cratering is a random process, the phenomena which occur as a result of cratering are best studied from a statistical point of view. It therefore behooves us to consider the average fluence properties of the regolith in attempting to understand the general characteristics of the lunar sedimentation processes.

We have considered the distribution of fluences in all the lunar soils which have been measured in this laboratory (Eugster et al., 1970; Burnett et al., 1971; Russ et al., 1972; Russ, 1972, 1973, 1974). This data represents the large majority of the low 
energy fluence measurements which have been made on lunar soils. Lugmair and Marti (1971) measured Gd isotopic abundances on five soils from the Apollo 12 and Apollo 14 sites. Their measured fluences fall within $1 \sigma$ of the mean fluence of the surface soils (Figure 8a).

Histograms of the normalized fluences are shown in Figure 8. Fluences in soils taken from depths shallower than $100 \mathrm{~g} \mathrm{~cm}^{-2}$ are plotted in Figure 8a. Included in the histogram is one sample from $100 \mathrm{~g} \mathrm{~cm}^{-2}$, two from $80 \mathrm{~g} \mathrm{~cm}^{-2}$ and the remainder from depths less than $65 \mathrm{~g} \mathrm{~cm}^{-2}$. The histogram defines a normal distribution with a mean value of $2.3 \times 10^{16} \mathrm{n} \mathrm{cm}^{-2}$. Samples which were taken directly from the surface are identified in the histogram by open boxes. Those materials which were taken from below the surface but shallower than $100 \mathrm{~g} \mathrm{~cm}^{-2}$ are plotted as cross hatched boxes. Inclusion of samples from shallow depths does not alter the distribution which is defined by the surface soils alone. Apparently the surface of the regolith has a high probability of being well mixed to depths on the order of $100 \mathrm{~g} \mathrm{~cm}^{-2}$ in periods of about 100 m.y. (approximately the minimum time which can be resolved by isotopic shifts of ${ }^{158} \mathrm{Gd} /{ }^{157} \mathrm{Gd}$ ).

There are seven samples in Figure 8a with neutron fluence less than $1.7 \times 10^{16} \mathrm{n} \mathrm{cm}^{-2}$. Five of these samples, identified by the filled boxes in Figure 8a, are clearly associated with deep fresh cratering events (the other two samples are from the white mantle at the base of the South Massif at the Apollo 17 site). The three samples from the top of the Apollo 17 deep drill stem have already been discussed at length. They are probably materials associated with the nearby deep craters (PET, 1973). Sample 72421 with a fluence of $0.5 \times 10^{16} \mathrm{n} \mathrm{cm}^{-2}$ was taken directly from the rim of Shorty crater, a fresh crater of $10-15 \mathrm{~m}$ depth. Sample 14141 has a fluence of $0.3 \times 10^{16} \mathrm{n}$ $\mathrm{cm}^{-2}$ (Russ, 1974). This soil was taken from the rim of Cone crater, a relatively young crater of about $70 \mathrm{~m}$ depth. The low neutron fluence in these five samples indicates that materials from considerably deeper than the nuclear active zone have had significantly less neutron exposure than soils taken from the top $500 \mathrm{~g} \mathrm{~cm}^{-2}$ of the regolith.

Soils from depths down to $\sim 500 \mathrm{~g} \mathrm{~cm}^{-2}$ were sampled by deep drill cores at three lunar sites. Fluences in soils from depths between $100 \mathrm{~g} \mathrm{~cm}^{-2}$ and $500 \mathrm{~g} \mathrm{~cm}^{-2}$ in these cores are plotted as a histogram in Figure $8 \mathrm{~b}$. A comparison of this histogram with that in Figure 8a shows that the deeper materials do not belong to the population distribution described by the near surface soils. Soils from depths between $100 \mathrm{~g} \mathrm{~cm}^{-2}$ and $500 \mathrm{~g} \mathrm{~cm}^{-2}$ have a mean value of $3.5 \times 10^{16} \mathrm{n} \mathrm{cm}^{-2}, 50 \%$ greater than the mean value of the near surface soils. These depths must have a relatively small probability of being mixed since two of the three samplings have neutron fluence profiles which reflect extended periods of undisturbed irradiation (Russ et al., 1972; Russ, 1973).

The first measurements on lunar soils from Apollo 11 showed that they had a much lower fluence than would be expected from irradiation within the top $\mathrm{kg} \mathrm{cm}^{-2}$ of the regolith for a period of 3-4 AE (Eugster et al., 1970b). This fundamental observation is found to be true for all lunar soils as can be seen from the histogram of fluences in Figure 8 . For instance, materials samples by the Luna 16 mission have a normalized 
neutron fluence of $4.6 \times 10^{16} \mathrm{n} \mathrm{cm}^{-2}$, the largest that has been measured in the lunar soils. Assuming the $\mathrm{LCH}$ calculations to be an accurate representation of the lunar neutron flux, this is about $75 \%$ of the fluence which would be obtained by materials confined to the top $\mathrm{kg} \mathrm{cm}^{-2}$ of the regolith for $\sim 3.8 \mathrm{AE}$. The paucity of highly irradiated soils indicates that deep mixing is a common phenomenon which dilutes irradiated material from the nuclear active zone with unirradiated materials from depths $\gtrsim 500 \mathrm{~g} \mathrm{~cm}^{-2}$.

Note in the histograms that fluences in materials from each site tend to cluster together to form narrowly defined populations within the broad distribution of all the materials. The clustering demonstrates the effects of specific local events and emphasizes the necessity to consider average properties from many regions in considering the overall characteristics of regolith transport processes. Local events produce narrowly defined distributions of fluence vertically as well as horizontally. This is apparent in the uniformity of the fluence profiles which have been observed in the deep drill stems, particularly those from Apollo 15 and Apollo 17. If the source of sedimenting material were not constrained to a narrow range of fluences the profiles which have been observed would be virtually obscured by variations in the predepositional fluences $\left(\psi_{0}\right)$. For instance, in Figure 9 we have superimposed a range of fluences on the data from the Apollo 17 and Apollo 15 deep drill cores which represents one standard deviation $\left( \pm 0.7 \times 10^{16} \mathrm{n} \mathrm{cm}^{-2}\right)$ of the surface soil distribution curve (Figure 8a). Obviously, if the values varied throughout this range, we would have difficulty identifying regularity in the depth profiles.

Conclusions: From the previous discussions we can attribute the following statistical characteristics to the fluence in the lunar regolith. (1) Restricted vertical and lateral regions have unique fluences which are a direct manifestation of the events which have produced the regolith in that particular lunar site. (2) There is a well-stirred surface layer which extends about $100 \mathrm{~g} \mathrm{~cm}^{-2}$ into the lunar regolith. (3) There has been an extended period of undisturbed stratification between materials which reside in the well-mixed surface layer and materials which were taken from depths between $100 \mathrm{~g} \mathrm{~cm}^{-2}$ and $500 \mathrm{~g} \mathrm{~cm}^{-2}$. The stratification is manifest by distinctly different neutron fluences in near surface soils $\left(2.3 \times 10^{16} \mathrm{n} \mathrm{cm}^{-2}\right)$ and soils from depths immediately below the surface layer $\left(3.5 \times 10^{16} \mathrm{n} \mathrm{cm}^{-2}\right)$. (4) Soils excavated from depths considerably below the nuclear active zone have very low neutron fluences. The few which have been measured have fluences $1-2 \times 10^{16} \mathrm{n} \mathrm{cm}^{-2}$ less than the mean fluence in the surface layer. (5) If the calculated lunar neutron flux of LCH (1972) is correct, deep mixing is a common lunar phenomenon which is responsible for relatively low neutron fluences in materials throughout the lunar regolith.

\section{Vertical Mixing Models}

Vertical mixing corresponds to excavating to depth, complete homogenization of the excavated material, and refilling the crater with the homogenized soils (with no differential lateral transport). 


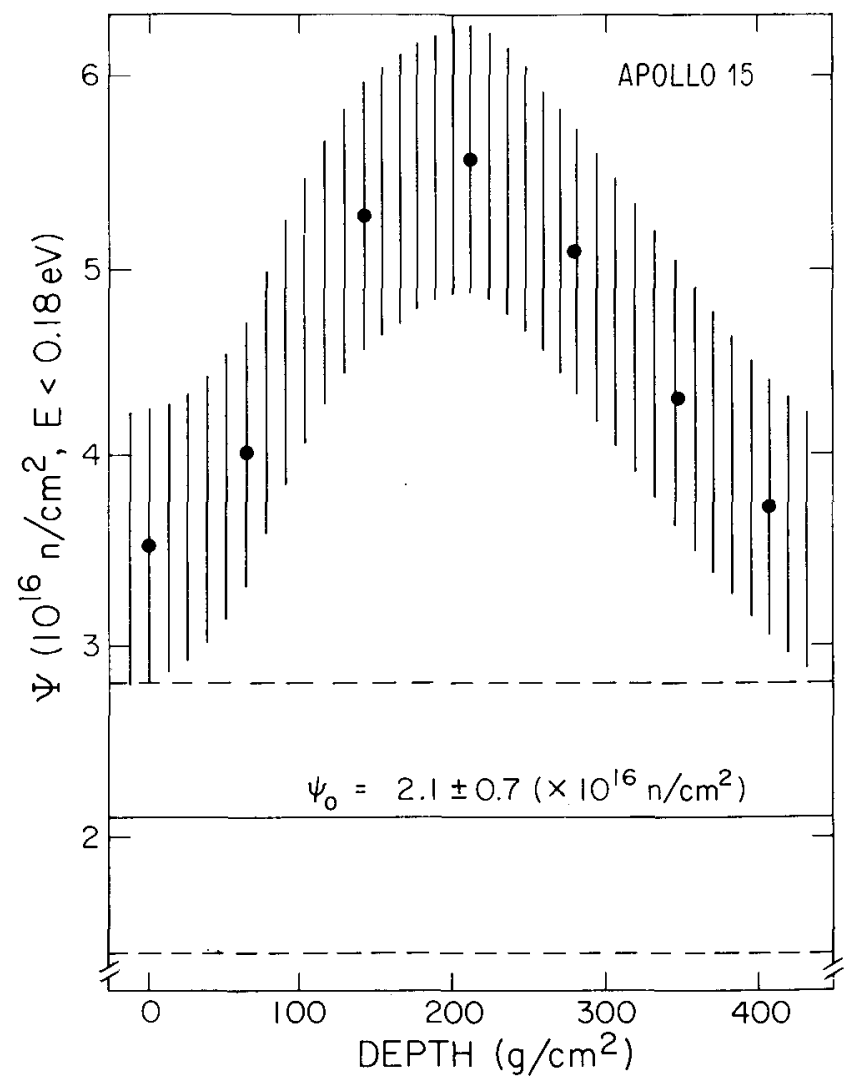

Fig. 9 b.

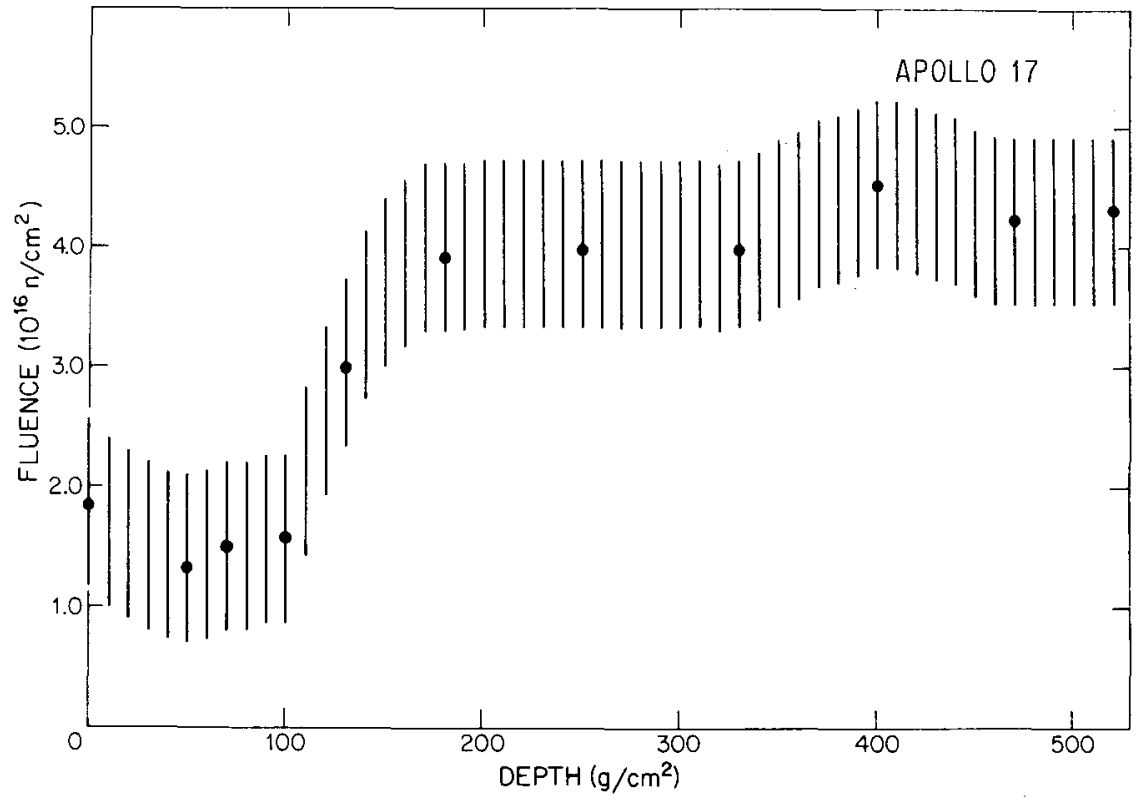

Fig. 9a.

Fig. 9a-b. A superposition of the $1 \sigma$ standard deviation of the fluence in all near surface soils upon the fluence profile in the Apollo 17 ( 9 a) and Apollo 15 ( $9 \mathrm{~b}$ ) deep drill stems. Note that the measured profiles definere markably smooth distributions within the broad range defined by the standard deviation. This indicates that large vertical sections of the drill stems were formed from materials which had a much narrower dispersion of neutron fluence than the total population of the surface soils. 


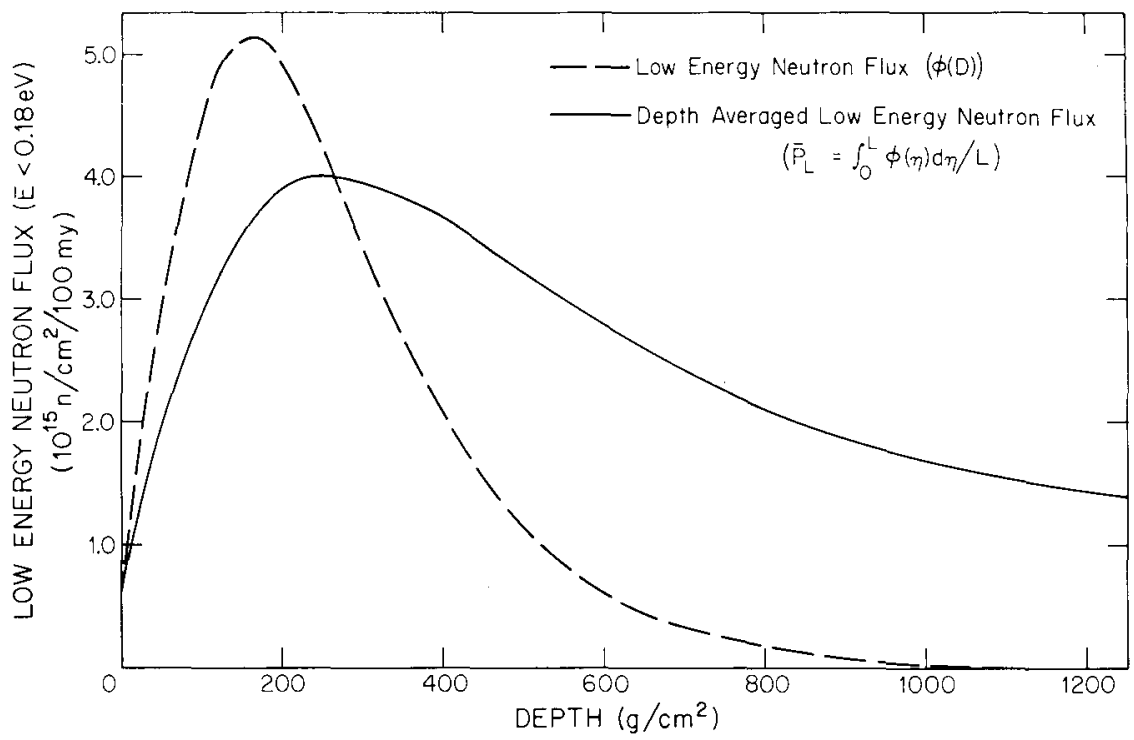

Fig. 10. The variation of the depth averaged low energy neutron flux $\left(\vec{P}_{L}=\left(\int_{0}^{L} \Phi(\eta) \mathrm{d} \eta / L\right)\right)$ as a function of depth in the lunar regolith.

This type of model is a convenient representation of the general concepts of lunar cratering transport and readily permits the calculation of transport parameters. The major difficulty with the model is that it requires that deep mixing and shallow mixing take place at the same site.

The neutron flux within a mixed layer is the depth averaged flux $\left(\bar{P}_{L} \equiv \int_{0}^{L} \Phi(\eta) \mathrm{d} \eta / L\right)$. The functional dependence between $\bar{P}_{L}$ and depth is shown in Figure 10. The averaged flux increases to a maximum at about $100 \mathrm{~g} \mathrm{~cm}^{-2}$ deeper than the maximum in the flux curve itself. The dispersion in values of $\bar{P}_{L}$ between $\sim 125 \mathrm{~g} \mathrm{~cm}^{-2}$ and $\sim 500 \mathrm{~g} \mathrm{~cm}^{-2}$ is sufficiently small that it may be considered a constant value through these depths (Russ et al., 1972); i.e., mixing to depths of $200 \mathrm{~g} \mathrm{~cm}^{-2}, 300 \mathrm{~g} \mathrm{~cm}^{-2}$, etc. will produce fluences within the mixed zone which are constant within the standard deviation of the fluences which have been measured. At depths greater than $\sim 750 \mathrm{~g} \mathrm{~cm}^{-2} \bar{P}_{L}$ decreases in direct proportion to $1 / L$.

Uniform mixing model: Previous considerations of the fluence in surface soils have treated the regolith as though it were instantaneously well mixed to depths of about $3 \mathrm{~kg} \mathrm{~cm}^{-2}$ (Equation (5)). This model demands that the fluence is constant throughout the depth of the mixed slab. This is clearly not descriptive of the differences in fluences which we observe between materials from shallow depths, intermediate depths and great depths in the lunar regolith.

Two layer mixing model: Consider a two layer mixing model which assumes that mixing to a depth much greater than the nuclear active zone occurs with a probability of $\alpha$ per unit time and that mixing within the nuclear active zone is instantaneous. This model yields fluences within the nuclear active zone which are greater than fluences 
from depths below the nuclear active zone because of an extended mean residence time $(1 / \alpha)$ in the region of high neutron production. This model is descriptive of observed differences in fluences between shallow materials and soils from great depths but it cannot account for the stratification of fluences between materials from depths less than $100 \mathrm{~g} \mathrm{~cm}^{-2}$ and fluences in soils from between $100 \mathrm{~g} \mathrm{~cm}^{-2}$ and $500 \mathrm{~g} \mathrm{~cm}^{-2}$.

Three layer mixing model: A three layer vertical mixing model is the simplest case which can be descriptive of the stratification of fluences within the shallow regions of the regolith. This model eliminates the assumption of infinitely rapid mixing within the nuclear active zone and permits the comparison of relative rates of deep and shallow mixing which are fundamental to the problem of lunar mixing.

Let the layers be labeled 1, 2, 3 and the depths of the boundaries between the layers as $L_{1}, L_{2}, L_{3}$. Layer 1 lies in the shallowest portion of the regolith and is mixed at an infinitely rapid rate. Let the probability of mixing to the bottom of layer 2 per unit time be $\alpha\left(1-f_{3}\right)$ and the probability of mixing to the bottom of $L_{3}$ be $\alpha f_{3}$, where $f_{3}<1$. The average fluences in each layer are given by the equations

$$
\begin{aligned}
& \bar{\psi}_{1}(T)=\bar{P}_{3} T+\left(\frac{\bar{P}_{2}-\bar{P}_{3}}{\alpha f_{3}}\right)\left(1-e^{-\alpha f_{3} T}\right)+\left(\frac{\bar{P}_{1}-\bar{P}_{2}}{\alpha}\right)\left(1-e^{-\alpha T}\right), \\
& \bar{\psi}_{2}(T)=\bar{P}_{3} T+\left(\frac{\bar{P}_{2}-\bar{P}_{3}}{\alpha f_{3}}\right)\left(1-e^{-\alpha f_{3} T}\right)-\frac{\left(\bar{P}_{1}-\bar{P}_{2}\right) L_{1}}{\alpha\left(L_{2}-L_{1}\right)}\left(1-e^{-\alpha T}\right), \\
& \bar{\psi}_{3}(T)=\bar{P}_{3} T+\frac{\left(\bar{P}_{2}-\bar{P}_{3}\right) L_{2}}{\alpha f_{3}\left(L_{3}-L_{2}\right)}\left(1-e^{-\alpha T}\right) .
\end{aligned}
$$

For long periods of time $(\alpha T \gg 1)$ the difference in fluence between layers 1 and 2 is given by

$$
\bar{\psi}_{1}-\bar{\psi}_{2}=\frac{\left(\bar{P}_{1}-\vec{P}_{2}\right) L_{2}}{\alpha\left(L_{2}-L_{1}\right)},
$$

and for very long periods of time $\left(\alpha f_{3} T \gg 1\right)$ the differences in fluence between layers 2 and 3 is given by

$$
\bar{\psi}_{2}-\bar{\psi}_{3}=\frac{\left(\bar{P}_{2}-\bar{P}_{3}\right) L_{3}}{\alpha f_{3}\left(L_{3}-L_{2}\right)}+\frac{\left(\bar{P}_{2}-\bar{P}_{1}\right) L_{1}}{\alpha\left(L_{2}-L_{1}\right)} .
$$

On the basis of our previous discussion of the statistical properties of neutron fluence in the regolith, we can infer values for many of the parameters in the equations. Layer 1 is the surface mixing layer with a depth $L_{1}$. From the previous discussion we had concluded that $L_{1} \lesssim 100 \mathrm{~g} \mathrm{~cm}^{-2}$. To obtain the difference $\psi_{1}-\psi_{2}$ let us take $L_{1}=50 \mathrm{~g} \mathrm{~cm}^{-2}$, the average fluence within this layer is $2.3 \times 10^{16} \mathrm{n} \mathrm{cm}^{-2}\left(\bar{\psi}_{1}\right)$. Layer 2 extends to the bottom of the nuclear active zone, a depth of about $500 \mathrm{~g} \mathrm{~cm}^{-2}$. The average fluence between $L_{1}$ and $L_{2}$ is $3.5 \times 10^{16} \mathrm{n} \mathrm{cm}^{-2}\left(\bar{\psi}_{2}\right)$. The depth averaged flux $\left(\bar{P}_{L}\right)$ is given in Figure 10. Using the above parameters in Equation (13), $\alpha$ is determined to be $0.14 / 100$ m.y. The functional relationship between $\left(\bar{P}_{2}-\bar{P}_{3}\right)$ and 
$\alpha f_{3}$ was examined graphically to determine values of $L_{3}$ and $\alpha f_{3}$ which are solutions to Equations (12). An upper limit on $\alpha f_{3}$ is given when $f_{3}=1$, a lower limit on solutions is given by $\vec{P}_{3}=0$. Using these limits, the range of acceptable solutions to Equations (12) is given by $0.09 / 100$ m.y. $<\alpha f_{3}<0.14 / 100$ m.y. or $0.64<f_{3}<1$. The corresponding depths of layer 3 are $\infty>L_{3}>4.1 \times 10^{3} \mathrm{~g} \mathrm{~cm}^{-2}$.

The result succinctly points out a contradiction that is inherent in the magnitude of the fluences as a function of depth. The large difference in fluence between materials in layers 1 and 2 is a manifestation of extended periods of stratification within the nuclear active zone. In contradistinction the absolute magnitude of fluence in soils taken from within the nuclear active zone demands relatively rapid turnover times to depths an order of magnitude greater than $500 \mathrm{~g} \mathrm{~cm}^{-2}$. The result of the analysis shows that the stratification time and the deep turnover time must be comparable $\left(\alpha \approx \alpha f_{3}\right)$ to produce the differences in fluences which we observe in the regolith. The solution demands that the probability of mixing to depths of several $\mathrm{kg} \mathrm{cm}^{-2}$ is commensurate with the probability of mixing to $0.5 \mathrm{~kg} \mathrm{~cm}^{-2}$. This result is in sharp contradiction to that obtained by any of the depth-cratering rate models currently in use (Shoemaker et al., 1970; Soderblom and Lebovsky, 1972; Gault et al., 1974). These models assume a power law which gives a rapid decrease in the rate of cratering with depth, and relates the rate of deep cratering to that of shallow cratering. Further, if our analysis is correct, the neutron fluence requires that excavation by impacts (both primary and secondary) for depths below $\sim 100 \mathrm{~g} \mathrm{~cm}^{-2}$ to several $\mathrm{kg} \mathrm{cm}^{-2}$ must be due to a completely independent population of infalling debris from that which causes mixing at shallower depths (less than $100 \mathrm{gm} \mathrm{cm}^{-2}$ ).

We have attempted to resolve the problem by considering the effects of changing different parameters within the context of the three layer mixing model. There are two considerations which might affect changes in the results of the model: (1) The duration of stratification within the nuclear active zone may be reduced by decreasing the difference between fluences in soils from layers 1 and 2 . Decreasing this difference to $\bar{\psi}_{2}-\bar{\psi}_{1}=6 \times 10^{15} \mathrm{n} \mathrm{cm}^{-2}$, half the value of the difference defined by the histograms in Figure 8, produces a result which is, for practical purposes, unchanged from the result derived from the original considerations. (2) Decreasing the flux from that calculated by LCH (1972) decreases the turnover time to great depths which is required to produce low fluences within the nuclear active zone. The LCH flux was decreased by half, the maximum decrease suggested by Woolum et al. (1974), and again the results were effectively unchanged from those obtained from the original premise.

Reduction of the $\mathrm{LCH}$ flux to about $30 \%$ of the original values constitutes a solution to the dilemma. In this instance $f_{3}=1$ when $L_{2}=L_{3}$, and solutions where $L_{3} \gg L_{2}$ give values of $f_{3} \ll 1$, i.e., the flux is sufficiently small that it is no longer necessary to invoke deep mixing to produce the magnitude of fluences which have been measured in materials from the nuclear active zone. The fluences would be the manifestation of residence in the nuclear active zone for periods of time comparable to the age of the mare. Differences in fluence between layers 1 and 2 could simply be the result of 
extended periods of static irradiation in the top $500 \mathrm{~g} \mathrm{~cm}^{-2}$ of the lunar regolith (Equation (1)). If the lunar flux were of the magnitude implied by this analysis it puts a limitation upon the maximum fluence which could be obtained in the lunar soil. Materials which resided for the entire age of the mare $(\sim 3.8 \mathrm{AE})$ at a depth corresponding to the peak in the flux curve would obtain a neutron fluence of $\sim 6 \times 10^{16} \mathrm{n} \mathrm{cm}^{-2}$ (assuming $\Sigma_{\text {eff }}=9.25 \times 10^{-2} \mathrm{~cm}^{2}$ ). This fluence is $30 \%$ greater than the largest which has been measured and there is no contradiction at this time. However, this limitation should be considered as more fluence measurements are made.

The extreme nature of the conclusions of this analysis of the stratification of fluence in the lunar soils may be the result of inadequacies of the vertical mixing model. Lateral transport of materials excavated by impacts deeper than the nuclear active zone can play a major role in the dilution of irradiated material with unirradiated material to produce the consistently low fluences observed in the regolith. Conversely, deep impacts, on the average, may have relatively little effect on mixing within the nuclear active zone.

Conclusions: An analysis of the vertical stratification of neutron fluence using a vertical mixing model suggests one of two alternative conclusions concerning the physical processes at the lunar surface; (1) The low energy neutron flux in the lunar regolith may be circa $30 \%$ of the value calculated by LCH (1972), an amount significantly less than suggested by Woolum et al. (1974). Such a reduction in the neutron flux would imply a quiescent regolith which has remained undisturbed within the nuclear active zone for periods of time comparable to the age of the mare. (2) Alternatively, the probability of mixing to depths of several hundred $\mathrm{g} \mathrm{cm}^{-2}$ must be nearly identical to the probability of mixing to several $\mathrm{kg} \mathrm{cm}^{-2}$ in contrast to the depth-rate of mixing relationships which are currently in use (Shoemaker et al., 1970; Soderblom and Lebovsky, 1972; Gault et al., 1974). If this is the case, the projectiles responsible for mixing to great depths are not the same population as the small projectiles responsible for cratering and mixing to depths less than $100 \mathrm{~g} \mathrm{~cm}^{-2}$. The disagreement between these conclusions and more conventional ideas concerning the physical processes in the lunar regolith may result from the failure to consider the lateral transport of materials in the mixing model.

\section{Summary and Conclusions}

Neutron fluences in soils taken from the Apollo 17 deep drill stem have a remarkably regular variation with depth in the lunar regolith (Figure 4). The depth dependence can be quantitatively described by a model of accretion of the section after which it was subject to an extended period of undisturbed irradiation, followed by recent mixing to shallow depths. Such depositional processes are similar to those postulated to describe the fluence profiles in the Apollo 15 (Russ et al., 1972) and Apollo 16 (Russ, 1973) deep drill stems. According to this model, this section of regolith is very old, the deepest materials having been emplaced $\sim 1.25 \mathrm{AE}$ ago. However, the model 
requires that the section be accreted from very lightly irradiated material. We cannot propose a continuous source of such material and thus consider this an implausible description of the depositional history.

Our inability to determine a feasible source of material for a model of in situ irradiation led us to consider a contrasting model. In the context of this model these soils represent a rapidly accreted section of regolith deposited in recent lunar history. The nearly constant fluence through thick sections of the drill stem allows us to estimate an upper limit of 100-200 m.y. on the age of emplacement. The neutron fluence is a manifestation of the irradiation history of the source material rather than fluences acquired subsequent to deposition. The layered structure reflects the existence of two thick sections of regolith, each being nearly homogeneous with respect to the isotopic abundances of $\mathrm{Gd}$ and Sm. Other characteristics of the soils, i.e., chemistry (Helmke et al., 1973), spallation products (Eberhardt et al., 1974), and petrographic properties (Heiken and McKay, 1974; PET, 1973) correlate with the depth dependence of the rare earth isotopes, suggesting thicknesses of material which are homogeneous with respect to a number of properties. Heavy ion track densities (Crozaz et al., 1974) in soils from 70008 are also compatible with this model. From many points of view a model of rapid accumulation of two distinctly different sources of material is a plausible depositional history for this section of regolith from the Taurus Littrow Valley.

The uniformity of properties through large sections of the drill stem provides the criteria for defining major stratigraphic intervals which are different from those identified by the Preliminary Examination Team (1974). The newly defined shallow interval extends from near the surface down to and including $100 \mathrm{~g} \mathrm{~cm}^{-2}$; an intermediate interval includes 125 and $180 \mathrm{~g} \mathrm{~cm}^{-2}$; and a deep stratigraphic interval includes the remainder of the drill stem.

All measured fluences in lunar soils have been normalized to irradiation in a standard chemical environment and plotted as histograms (Figure 8). The histogram of fluences in soils taken from the surface and near surface (Figure 8a) indicates a well mixed surface layer extending no more than $100 \mathrm{~g} \mathrm{~cm}^{-2}$ depth. The average normalized fluence in this layer is $2.3 \times 10^{16} \mathrm{n} \mathrm{cm}^{-2}$. Materials taken from below this surface layer down to $\sim 500 \mathrm{~g} \mathrm{~cm}^{-2}$ have an average fluence of $3.5 \times 10^{16} \mathrm{n} \mathrm{cm}^{-2}$, significantly greater than in the surface layer. This zone is apparently less likely to have been mixed than the surface layer, since two of the three samplings have fluence profiles suggesting extended periods of in situ irradiation (Russ et al., 1972; Russ, 1973). Fluences in soils believed to be fresh impact debris from deep craters indicate that soils at great depths have very low neutron fluences $\left(<10^{16} \mathrm{n} \mathrm{cm}^{-2}\right)$.

Our analysis of the apparent vertical stratification of neutron fluence in the regolith, using a three-layer vertical mixing model, indicates the probability of mixing to depths of several hundred $\mathrm{g} \mathrm{cm}^{-2}$ is virtually identical to the probability of mixing to several $\mathrm{kg} \mathrm{cm}^{-2}$. This is in sharp contrast to most of the models currently in use which assume a power law to relate the rate of cratering to the depth of cratering. If our analysis is correct, the excavation by impacts to depths below $\sim 100 \mathrm{~g} \mathrm{~cm}^{-2}$ to several $\mathrm{kg} \mathrm{cm}^{-2}$ 
must be due to an independent population of infalling debris with a characteristic size distribution which is distinct from that which mixes the shallow depths $\left(<100 \mathrm{~g} \mathrm{~cm}^{-2}\right)$.

It becomes unnecessary to invoke independent populations of impacting bodies if the theoretical ${ }^{157} \mathrm{Gd}$ capture rate calculated by LCH (1972) was about three times greater than the actual capture rate in the regolith. This is a larger reduction than was suggested by Woolum et al. (1975) based upon discrepancies between the neutron energy spectrum calculated by LCH (1972) and the actual energy spectrum in the regolith inferred by experiments.

It is likely that the vertical mixing model is an inadequate description of the regolith mixing processes and the conclusions are incorrect because of deficiencies in the model. A model which considers the lateral transport of materials excavated by relatively rare impacts which penetrate deeper than the nuclear active zone may provide a better description of the regolith mixing processes. A model of this type is currently being considered at our laboratory.

\section{Appendix I}

Lingenfelter et al. (1972) calculated the neutron flux spectrum and resultant capture rates for a variety of nuclides in lunar surface material. The data in this appendix provides the means to calculate the low-energy neutron flux $(E<0.18 \mathrm{eV})$ using the $\mathrm{LCH}$ capture rates for ${ }^{157} \mathrm{Gd}$.

The magnitude of the low energy neutron flux is dependent upon the neutron capture cross section of the chemical elements which comprise the irradiated material. The effect of chemical composition on the neutron flux is characterized by the macroscopic cross section $\left(\Sigma_{\text {eff }}\right)$ which is calculated using Equation (1A)

$$
\Sigma_{\text {eff }}=\sum X_{i} \sigma_{i}+\sum X_{j}^{\prime} \sigma_{j}^{\prime} .
$$

\section{TABLE VI}

Cross-sections for elements with $1 / v$ dependent capture cross-sections

\begin{tabular}{ll} 
Element & $\begin{array}{l}\text { Cross-section }\left(\sigma_{i}\right) \\
\left(10^{-24} \mathrm{~cm}^{2}\right)\end{array}$ \\
\hline $\mathrm{Si}$ & 0.16 \\
$\mathrm{Ti}$ & 6.1 \\
$\mathrm{Al}$ & 0.23 \\
$\mathrm{Fe}$ & 2.53 \\
$\mathrm{Cr}$ & 3.1 \\
$\mathrm{Mn}$ & 13.3 \\
$\mathrm{Mg}$ & 0.063 \\
$\mathrm{Ca}$ & 0.43 \\
$\mathrm{Na}$ & 0.53 \\
$\mathrm{~K}$ & 2.1 \\
\end{tabular}




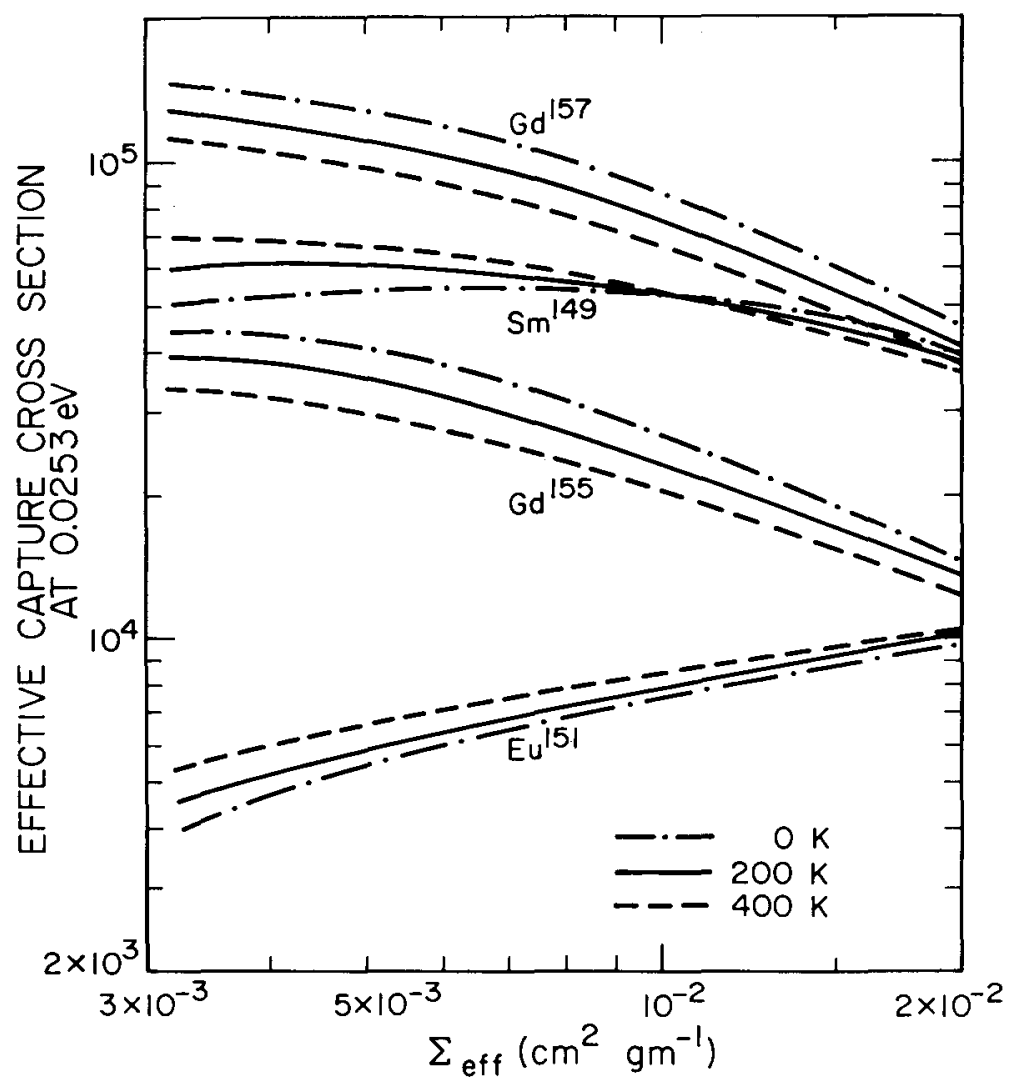

Fig. 11. Variation of the effective capture cross section for $0.0253 \mathrm{eV}$ neutrons as a function of the chemical composition of the irradiated material $\left(\Sigma_{\text {eff }}\right)$ for elements with thermal and epithermal resonance capture cross sections. (Reproduced unaltered from Lingenfelter et al. (1972).)

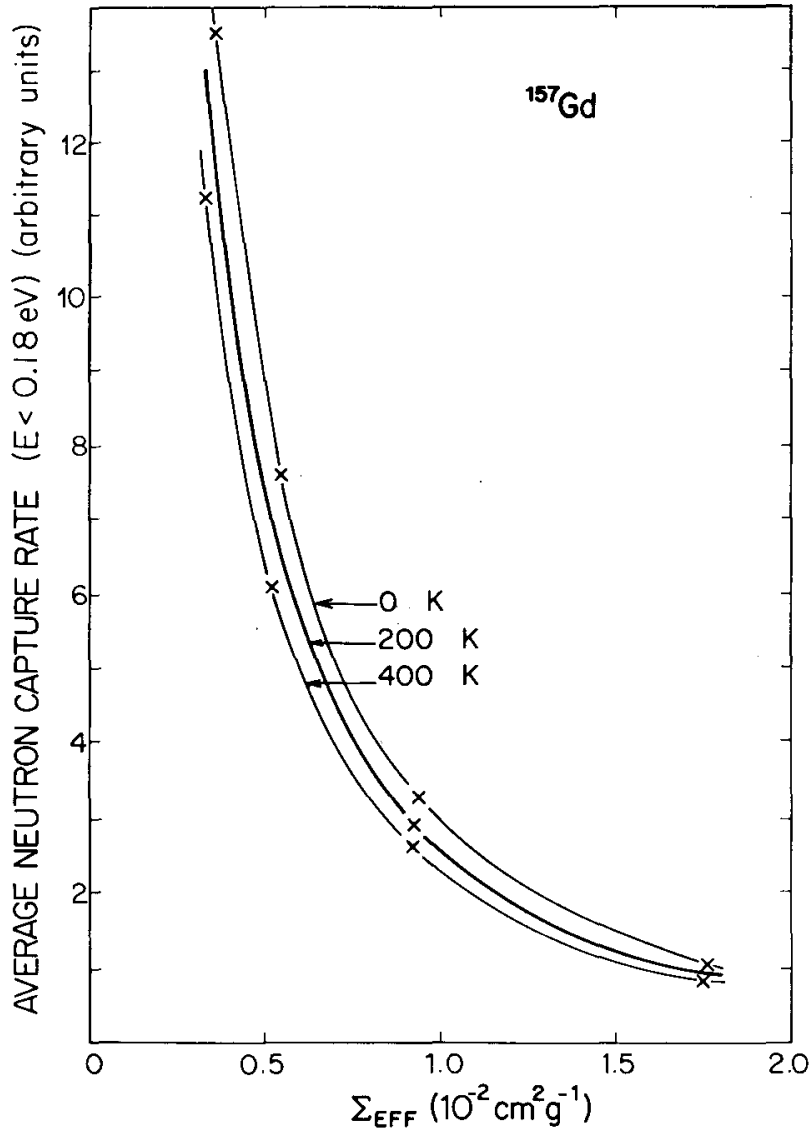

Fig. 12 Change in the relative average capture rate of ${ }^{157} \mathrm{Gd}$ as a function of the chemical composition of the irradiated material ( $\left.\Sigma_{\text {eff }}\right)$. (Reproduced from Russ (1974).) 
$X$ and $X^{\prime}$ are the number of atoms of element $i$ or $j$ per gram of irradiated material; $\sigma_{i}$ is the capture cross section for $0.0253 \mathrm{eV}$ neutrons of elements which have a cross section that varies in proportion to $1 / v$ (the velocity of neutrons). Values of $\sigma_{i}$ are given in Table VI $\sigma^{\prime}$ is the effective capture cross section at $0.0253 \mathrm{eV}$ for elements with thermal and epithermal resonance capture cross sections. This quantity varies as a function of $\Sigma_{\text {eff }}$ and therefore it must be determined by iteration. Using a value of $\Sigma_{\text {eff }}$ calculated only from elements with $1 / v$-dependent cross sections, values of $\sigma^{\prime}$ are determined from Figure 11. A new value of $\Sigma_{\text {eff }}$ is calculated which includes the contribution of nuclei with resonance capture cross sections. New values of $\sigma^{\prime}$ are taken from Figure 11 using this new value of $\Sigma_{\text {eff. }}$ The macroscopic capture cross section is

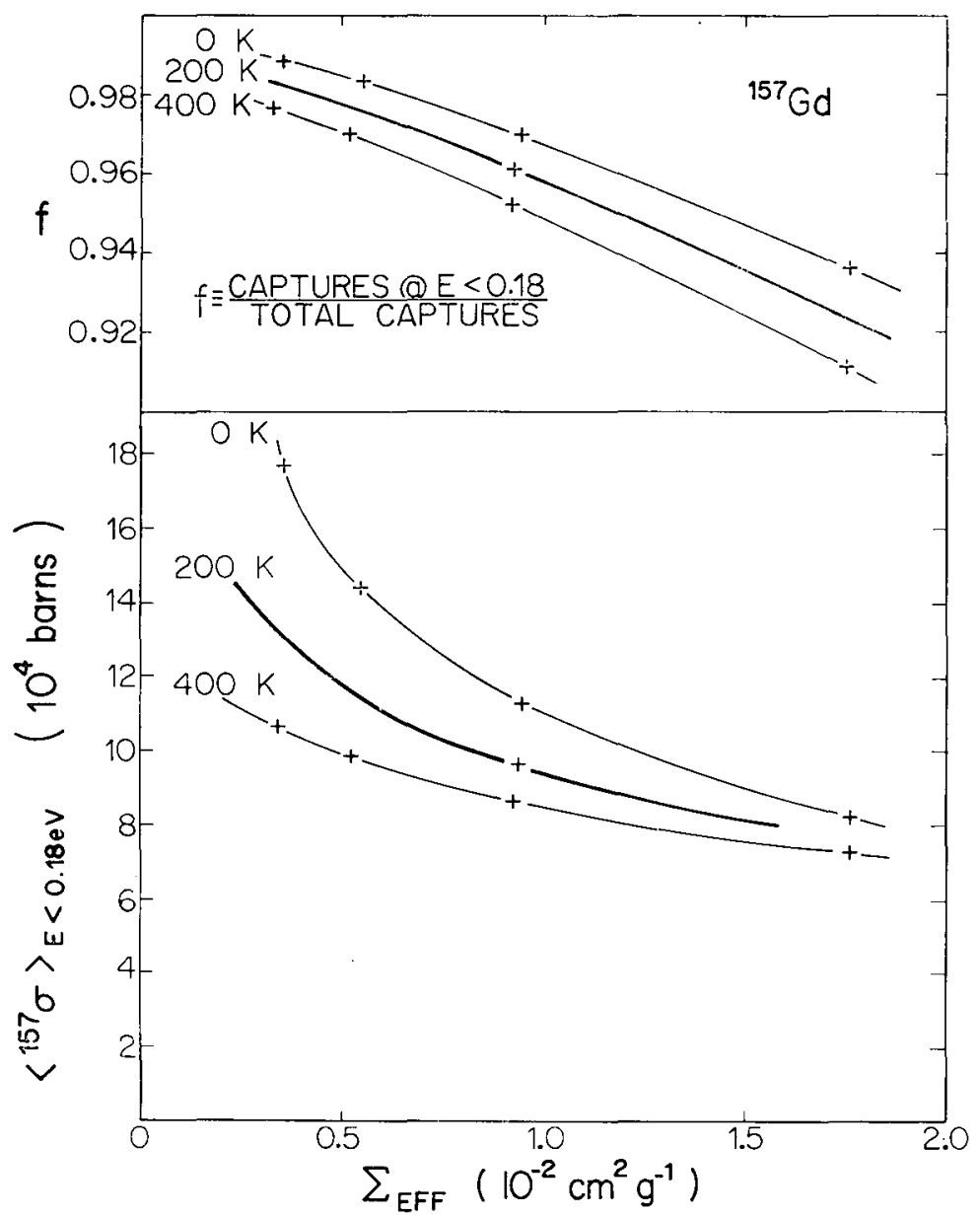

Fig. 13. Upper diagram shows the change in the fraction of total neutron captures by ${ }^{157} \mathrm{Gd}$ for neutrons with $E<0.18 \mathrm{eV}$ as a function of the chemical composition of the irradiated material $\left(\Sigma_{\mathrm{eft}}\right)$. Similarly, the lower diagram shows the functional dependence between the average ${ }^{157} \mathrm{Gd}$ capture cross section for neutrons with $E<0.18 \mathrm{eV}$ and the chemical composition.

(Reproduced from Russ, 1974). 
recalculated with new values of $\sigma^{\prime}$ and the iteration is continued until the result converges.

Lingenfelter et al. (1972) calculated the lunar neutron flux assuming the scattering medium to be an ideal gas. The families of curves in Figures 11, 12, and 13 show the effect of temperature on the low energy neutron flux using the ideal gas assumption. Calculations in this paper used the curves labeled $200 \mathrm{~K}$ to calculate the lunar flux.

The temperature effects are probably less important in determining the low energy neutron flux than the effects of neutron scattering from the crystalline lattices of materials in the lunar soil. Lattice scattering will cause the low energy neutron energy spectrum to deviate from the Maxwell-Boltzmann distribution which was used by LCH. Williams (1966) indicates that consideration of crystalline lattice effects will result in a spectrum which is shifted to high energies relative to the ideal gas. The shift manifests the poorer thermalization properties of crystalline materials. Failure to consider crystalline lattice effects may be a major cause of the discrepancies between

\section{TABLE VII}

${ }^{157} \mathrm{Gd}$ capture rates in lunar soil with arbitrary standard chemical composition $\left(\Sigma_{\mathrm{eff}}=9.25 \times 10^{-2}\right.$ $\left.\mathrm{cm}^{2} \mathrm{~g}^{-1}\right)^{\mathrm{a}}$

\begin{tabular}{|c|c|c|c|}
\hline Depth & $\begin{array}{l}\text { Capture rate } \\
\left(10^{20} \mathrm{n} \text {-barn } /\left(\mathrm{cm}^{2}-100 \text { m.y. }\right)\right)\end{array}$ & $\begin{array}{l}\text { Depth } \\
\left(\mathrm{g} \mathrm{cm}^{-2}\right)\end{array}$ & $\begin{array}{l}\text { capture rate } \\
\left(10^{20} \mathrm{n} \text {-barn } /\left(\mathrm{cm}^{2}-100 \text { m.y. }\right)\right)\end{array}$ \\
\hline 10 & 0.63 & 250 & 4.28 \\
\hline 20 & 1.18 & 260 & 4.12 \\
\hline 30 & 1.80 & 270 & 3.98 \\
\hline 40 & 2.28 & 280 & 3.81 \\
\hline 50 & 2.75 & 290 & 3.66 \\
\hline 60 & 3.17 & 300 & 3.51 \\
\hline 70 & 3.55 & 310 & 3.35 \\
\hline 80 & 3.96 & 320 & 3.19 \\
\hline 90 & 4.26 & 330 & 3.04 \\
\hline 100 & 4.50 & 340 & 2.88 \\
\hline 110 & 4.71 & 350 & 2.72 \\
\hline 120 & 4.87 & 400 & 2.06 \\
\hline 130 & 5.03 & 450 & 1.54 \\
\hline 140 & 5.12 & 500 & 1.15 \\
\hline 150 & 5.17 & 550 & 0.85 \\
\hline 160 & 5.20 & 600 & 0.62 \\
\hline 170 & 5.17 & 650 & 0.46 \\
\hline 180 & 5.14 & 700 & 0.34 \\
\hline 190 & 5.06 & 750 & 0.24 \\
\hline 200 & 4.97 & 800 & 0.18 \\
\hline 210 & 4.85 & 850 & 0.13 \\
\hline 220 & 4.73 & 900 & 0.09 \\
\hline 230 & 4.59 & 950 & 0.06 \\
\hline 240 & 4.45 & 1000 & 0.03 \\
\hline
\end{tabular}

Calculations by Lingenfelter et al. (1972) as compiled and modified by Russ (1974). 
the LCH neutron spectrum and the properties of the lunar neutron spectrum which has been inferred from experiments (Woolum et al., 1975).

Table VII is the low energy neutron capture rate $(A)_{s t}$ of ${ }^{157} \mathrm{Gd}$ as a function of depth in the lunar surface for $\Sigma_{\text {eff }}=9.25 \times 10^{-2} \mathrm{~cm}^{2} \mathrm{~g}^{-1}$. The low energy neutron flux may be calculated using Equation (2A)

$$
\phi_{i}=\frac{A_{s t}\left(A_{i} / A_{s t}\right) f_{i}}{\left\langle\sigma_{157(i)}\right\rangle}
$$

$\phi_{i}$ is the low energy neutron flux/100 m.y. $(E<0.18 \mathrm{eV}) ; A_{s t}$ is the ${ }^{157} \mathrm{Gd}$ capture rate for $\Sigma_{\text {eff }}=9.25 \times 10^{-2} \mathrm{~cm}^{2} \mathrm{~g}^{-1}$ taken from Table VII $\left(A_{i} / A_{s t}\right)$ is the ratio of the ${ }^{157} \mathrm{Gd}$ capture rate for a particular chemical environment $\left(\Sigma_{\text {eff }(i)}\right)$ over the capture rate in a standard chemical environment $\left(\Sigma_{\text {eff }(s t)}=9.25 \times 10^{-2} \mathrm{~cm}^{2} \mathrm{~g}^{-1}\right)$. The relative capture rates as a function of $\Sigma_{\text {eff }}$ are given in Figure 12: $f_{i}$ is the fraction of total neutron captures for neutrons with $E<0.18 \mathrm{eV}$ and $\left\langle\sigma_{157(i)}\right\rangle$ is the average ${ }^{157} \mathrm{Gd}$ neutron capture cross section (in barns) for $E<0.18 \mathrm{eV}$ neutrons. Values for these two quantities are taken from Figure 13.

Measured fluences were normalized for purposes of intercomparison of samples irradiated in different chemical environments. The normalization was accomplished by dividing the measured fluence by the ratio of the flux in the environment defined by the chemical composition of the sample over the flux in a standard chemical environment $\left(\phi_{i} / \phi_{s t}\right)$.

\section{Acknowledgment}

We are grateful to Price Russ for many helpful discussions in addition to passing on the experimental techniques, and for his thoughtful review of this paper. Jack Huneke was of great assistance in understanding problems involving the rare gases and conversations with Don Burnett helped in clarifying many points. This work was supported by the National Aeronautics and Space Administration under grant NGL-05-002-188.

\section{References}

Apollo 17 Lunar Sample Information Catalog: 1973, Lunar Receiving Laboratory (MSC 03211). Apollo 17 Preliminary Examination Team: 1973, Science 182, 659-672.

Armstrong, T. W. and Alsmiller, R. G., Jr.: 1971, Proc. Second Lunar Sci. Conf. 2, 1729-1745.

Bogard, D. C., Nyquist, L. E., Hissek, W. C., and Moore, D. R.: 1973, Earth Planetary Sci. Letters 21, 52-69.

Brunfelt, A. O., Heier, K. S., Nilssen, B., Steinnes, E., and Sundvall, B.: 1974, Lunar Science V, 92-94.

Burnett, D. S. and Woolum, Dorothy, S.: 1974, Proc. Fifth Lunar Sci. Conf. 2, 2061-2074.

Burnett, D. S., Huneke, J. C., Podosek, F. A., Russ, G. Price, III, and Wasserburg, G. J.: 1971, Proc. Second Lunar Sci. Conf. 2, 1671-1679.

Crozaz, G., Drozd, R., Hohenberg, C., Morgan, C., Ralston, C., Walker, R., and Yuhas, D.: 1974, Proc. Fifth Lunar Sci. Conf. 3, 2475-2499.

Duke, M. B. and Nagle, J. S.: 1974, Lunar Core Catalog (JSC 09252), 16-17.

Duncan, A. R., Erlank, A. J., Willis, J. P., and Sher, M. K.: 1974, Lunar Science V, 184-186. 
Eberhardt, P., Eugster, O., Geiss, J., Graf, H., Grogler, N., Guggisberg, S., Jungch, M., Maurer, P., Morgeli, M., and Stettler, A.: 1974, Lunar Science V, 197-199.

Eugster, O., Tera, F., Burnett, D. S., and Wasserburg, G. J.: 1970a, J. Geophys. Res. 75, 2753-2768.

Eugster, O., Tera, F., Burnett, D. S., and Wasserburg, G. J.: 1970b, Earth Planetary Sci. Letters 8, 20-30.

Gault, D. E., Horz, F., Brownlee, D. E., and Hartung, J. B.: 1974, Proc. Fifth Lunar Sci. Conf. 3, 2365- 2386.

Heiken, Grant and McKay, David S.: 1974, Proc. Fifth Lunar Sci. Conf. 1, 843-860.

Huneke, J. C., Podosek, F. A., Burnett, D. S., and Wasserburg, G. J.: 1972, Geochim. Cosmochim. Acta 36, 269-301.

Helmke, Philip A., Blanchard, Douglas P., Jacobs, Jeffrey W., Telander, Karen M., and Haskin, Larry A.: 1973, EOS 54, 595.

Kornblum, J. J., Fireman, E. L., Levine, M., and Aronson, A. : 1973, Proc. Fourth Lunar Sci. Conf., 2, 2171-2186.

Lingenfelter, R. E., Canfield, E. H., and Hess, W. N.: 1961, J. Geophys. Res. 66, 2665-2671.

Lingenfelter, R. E., Canfield, E. H., and Hampel, V. E.: 1972, Earth Planetary Sci. Letters 16, 355-369.

Lugmair, G. W. and Marti, K.: 1971, Earth Planetary Sci. Letters 13, 32-42.

Nagle, J. S.: 1974, (personal communication).

Pepin, R. O., Basford, J. R., Dragon, J. C., Coscio, M. R., Jr., and Murthy, V. R. : 1974, Proc. Fifth Lunar Sci. Conf. 2, 2149-2182.

Philpotts, J. A., Schumann, S., Schnetzler, C. C., Kouns, C. W., Doan, A. S., Jr., Wood, F. M., Jr., Bichel, A. L., and Lum Staab, R. K. L.: 1973, EOS 54, 603-604.

Russ, G. P., III: 1972, Earth Planetary Sci. Letters 13, 384-386.

Russ, G. P., III : 1973, Earth Planetary Sci. Letters 19, 275-289.

Russ, G. P., III: 1974, Neutron Stratigraphy in the Lunar Regolith, Ph.D. Thesis, California Institute of Technology.

Russ, G. P., III, Burnett, D. S., and Wasserburg, G. J.: 1972, Earth Planetary Sci. Letters, 15, 172-186.

Russ, G. P., III, Burnett, D. S., Lingenfelter, R. E., and Wasserburg, G. J.: 1971, Earth Planetary Sci. Letters 13, 53-60.

Shoemaker, E. M., Hart, M. H., Swann, G. A., Schleicher, D. L., Dahlem, D. H., Schaber, G. G., and Sutton, R. L.: 1970, Science 167, 452-455.

Soderblom, Laurence A. and Lebovsky, Larry A.: 1972, J. Geophys. Res. 77, 279-294.

Williams, M. M. R.: 1966, The Slowing Down and Thermalization of Neutrons, North-Holland, p. 93.

Woolum, Dorothy, S., Burnett, D. S., Furst, Marion, and Weiss, J. R.: 1975, The Moon, (in press). 